\title{
ESTUDO SOBRE ACOLHIMENTO ÀS VÍTIMAS DE VIOLÊNCIA DOMÉSTICA EM JUIZ DE FORA/MG
}

\section{ARTIGO ORIGINAL}

LEITE, Nádia Gonçalves ${ }^{1}$, RIBEIRO, Filipe Leonardo Oliveira²

LEITE, Nádia Gonçalves. RIBEIRO, Filipe Leonardo Oliveira. Estudo sobre acolhimento às vítimas de violência doméstica em Juiz de Fora/MG. Revista Científica Multidisciplinar Núcleo do Conhecimento. Ano. 06, Ed. 11, Vol. 06, pp. 94119. Novembro 2021. ISSN: 2448-0959, Link de acesso: https://www.nucleodoconhecimento.com.br/arquitetura/acolhimento-as-vitimas, DOI: 10.32749/nucleodoconhecimento.com.br/arquitetura/acolhimento-as-vitimas

\section{RESUMO}

Este trabalho tem como problemática a realidade e 0 acolhimento às mulheres da cidade de Juiz de Fora - MG que enfrentam rotineiramente a violência doméstica, seja ela física, psicológica, sexual, moral ou patrimonial. A maioria das mulheres que passa por essa situação, mostra temor ao denunciar, muitas vezes pela dependência financeira ao dedicar-se à vida familiar e doméstica e, mesmo com a legislação promulgada a fim de protegê-las, muitas vezes não é fornecido o apoio adequado, resultante da escassez de acolhimento, há a necessidade de incorporação dessas Casas-Abrigo para um suporte mais eficaz. Tem como objetivo geral, debater, coletar informações sobre o acolhimento às vítimas de violência doméstica em Juiz de Fora, pesquisar sobre a legislação em relação à proteção das vítimas de violência doméstica e o aumento de notificações de ocorrências, auxiliando futuros estudos e projetos de Centros de Apoio, e, posteriormente, sugestionar a localidade para um espaço de acolhimento na cidade de Juiz de Fora.

\footnotetext{
${ }^{1}$ Pós graduanda em Arquitetura e Cidades pela Faculdade Venda Nova do Imigrante (FAVENI). Graduada em Arquitetura e Urbanismo pela Rede de Ensino Doctum.

${ }^{2}$ Mestre em Ambiente Construído e especialista em Análise Ambiental pela Universidade Federal de Juiz de Fora (UFJF) e graduado em Arquitetura e Urbanismo pelo CES-JF.
}

RC: 101075

Disponível em: https://www.nucleodoconhecimento.com.br/arquitetura/acolhimentoas-vitimas 
As metodologias utilizadas para o desenvolvimento foram levantamentos de pesquisas bibliográficas e estudos de caso sobre o funcionamento de Casas-Abrigo já existentes no Brasil e em Juiz de Fora. Este trabalho, portanto, incorpora os dados obtidos por meio da pesquisa, para fomentar discussões e a criação de espaços para acolher essas mulheres e seus filhos. Inicialmente será abordado dados sobre a violência doméstica brasileira, alguns programas e Casas-Abrigo já existentes em solo brasileiro e a proposta de construção de uma Casa - Abrigo na região central de Juiz de Fora, onde de acordo com o estudo realizado, seria fundamental sua inserção.

Palavras-chave: Violência Doméstica, Feminicídio, Centro de Apoio, Arquitetura de Refúgio, Juiz de Fora.

\section{INTRODUÇÃO}

A violência doméstica é um assunto intrigante, que compreende a vida de crianças, adolescentes, idosos e mulheres mundialmente, resultante da desigualdade e discriminação de gênero presente nas relações de poder. Os dados mais alarmantes ainda recaem sobre as mulheres. Uma das imagens mais associadas à violência doméstica e familiar contra elas é a do homem - namorado, marido ou ex-marido que agride a parceira, motivado por um sentimento de posse sobre a vida e as escolhas daquela mulher (DOSSIÊ DE VIOLÊNCIA CONTRA AS MULHERES, 2014).

A violência contra as mulheres no Brasil é uma questão histórica e cultural, que ainda hoje, faz parte da realidade de muitos lares brasileiros. Com a entrada em vigor da Lei 11.340/2006, também conhecida como Maria da Penha, almeja-se que essa realidade mude e a mulher tenha instrumentos legais inibitórios, para que não seja vítima de discriminação, violência e ofensas dos mais variados tipos (RIOS, 2013). A Lei Maria da Penha, sancionada em 7 de agosto de 2006 pelo presidente Luiz Inácio Lula da Silva, tem como fundamento o combate ao feminicídio e a violência doméstica. A Lei recebeu esse nome devido à violência e tentativas de 
feminicídio sofridas por Maria da Penha Maia Fernandes, cearense e farmacêutica bioquímica, ao longo de 23 anos de casamento, por seu marido Marco Antônio Heredia Viveros (INSTITUTO MARIA DA PENHA, 2018).

Apesar disso, de acordo com a matéria publicada no site Brasil de Fato no ano de 2018, muitas mulheres continuam desassistidas sem saber onde buscar ajuda muitas das vezes, e não há apoio adequado de pessoas próximas e autoridades. A violência de gênero é transmitida de gerações, configurando modelos de corpos sociais patriarcais, de acordo com o livro Feminismo e Política (MIGUEL; BIROLI 2014). À vista disso, o conteúdo do artigo contribui com a criação de mecanismos concretos que amparam essas mulheres que sofreram ou ainda vêm sofrendo com tal ocorrência, através das pesquisas e dos dados apresentados.

O artigo tem como objetivo geral, debater, coletar informações sobre o acolhimento às vítimas de violência doméstica em Juiz de Fora, pesquisar sobre a legislação em relação à proteção das vítimas de violência doméstica, o aumento de notificações de ocorrências, auxiliando futuros estudos e projetos de Centros de Apoio, e, posteriormente, sugestionar a localidade para um espaço de acolhimento na cidade de Juiz de Fora.

Tem como objetivos específicos: Investigar a evolução e a contribuição do sistema político para a assistência das mulheres desprotegidas pela violência doméstica; Observar nos materiais investigados, se as vítimas recebem o devido tratamento e amparo, de acordo com a Lei; Analisar estudos de caso sobre centros de apoio à mulheres em situações vulneráveis de violência; Absorver os programas de necessidades oferecidos e apresentados pelas Casas-Abrigo já existentes em solo brasileiro; Fomentar discussões e estudos acerca da temática envolvendo violência doméstica e sobre importância das casas de acolhimento; Propor a futura construção de uma Casa - Abrigo na região central de Juiz de Fora, onde é a melhor localidade para a inserção, de acordo com o estudo apresentado no decorrer do artigo. 


\section{MÉTODO}

Os métodos empregados para o desenvolver do artigo foram pesquisas bibliográficas, permitindo detalhar e aprofundar na temática da violência doméstica, bem como questões da sociedade patriarcal e da legislação. São importantes, também, para a compreensão da finalidade de todo o conteúdo, mensurando e comprovando, em números, os referenciais claros e diretos sobre a violência doméstica.

Materiais como artigos, notícias comprobatórias, monografias, também fizeram parte do acervo das pesquisas contidas no referido trabalho, reforçando e ampliando a argumentação necessária para o desenvolvimento. As análises e coletas sobre opiniões públicas feitas pelo Senado Federal em 2017 através de entrevista telefônica com mulheres a partir de 16 anos com acesso à telefone móvel e fixo, da mesma forma, é responsável pela apuração de respostas concretas induzindo à temática proposta.

A elaboração de estudos de casos também foi feita para análises, a fim de pesquisar as propostas das Casas-Abrigo já existentes no Brasil e o funcionamento dos programas internos desses centros. Os dois projetos que refugiam mulheres vítimas de violência doméstica foram: a Casa Abrigo Lar da Mulher e a Casa Abrigo Canto de Dália.

Posteriormente foram realizadas no município de Juiz de Fora, análises e pesquisas sobre a violência doméstica associado à localidade para a proposta pontual de inserção de uma Casa - Abrigo.

\section{DESENVOLVIMENTO}

\subsection{DADOS SOBRE A VIOLÊNCIA DOMÉSTICA BRASILEIRA}

O maior receio das mulheres que não denunciam a agressão e o abuso é o medo dos agressores, seja por vingança, perseguição, humilhação, pela ausência ou

RC: 101075

Disponível em: https://www.nucleodoconhecimento.com.br/arquitetura/acolhimentoas-vitimas 
ineficácia de punição, dependência financeira, entre outras questões, como é apresentado nas tabelas 1, 2 e 3 a seguir, a qual confere $71 \%$ das justificativas, em 1116 respondentes da pesquisa feita pelo Senado Federal (2017). De acordo com Gouveia (2008), o caso das mulheres dificulta em consequência de elas serem maioria entre os(as) desempregados(as) ou no trabalho informal e precário.

Outra razão enfática para a não denúncia é a preocupação com a criação dos filhos com $32 \%$ do total (tabelas 1, 2 e 3), pois conforme apontado por Badinter, em 1980, o valor dado à maternidade contribui para o limite na autonomia das mulheres, em consequência dos padrões sociais de opressão que são ocultados, por esse motivo, tanto essas restrições quanto a maternidade têm valores positivos, promovendo um cenário de gêneros convencionais, conferindo dependência em relação ao agressor.

Tabela 1 - O que leva uma mulher a não denunciar a agressão? (Renda, Ocupação e Filhos)

\begin{tabular}{|c|c|c|c|c|c|c|c|c|c|c|}
\hline \multirow[t]{2}{*}{$\begin{array}{l}\text { To } \\
\text { al }\end{array}$} & \multicolumn{2}{|c|}{$\begin{array}{l}\text { Você já } \\
\text { sofreu } \\
\text { algum } \\
\text { tipo de } \\
\text { violênci } \\
\text { a } \\
\text { domésti } \\
\text { ca ou } \\
\text { familiar } \\
\text { provoca } \\
\text { da por } \\
\text { um } \\
\text { homem? }\end{array}$} & \multicolumn{3}{|c|}{ Renda } & \multicolumn{3}{|c|}{ Ocupação } & \multicolumn{2}{|c|}{$\begin{array}{l}\text { Você } \\
\text { tem } \\
\text { filhos? }\end{array}$} \\
\hline & s & $\begin{array}{l}\text { Nã } \\
\text { o }\end{array}$ & $\begin{array}{l}\mathrm{Se} \\
\mathrm{m}\end{array}$ & $A$ & & & $\begin{array}{l}\text { Exerce } \\
\text { trabalho }\end{array}$ & $\begin{array}{l}\text { Não } \\
\text { exerce }\end{array}$ & $\mathrm{m}$ & $\begin{array}{l}\text { Nã } \\
\text { o }\end{array}$ \\
\hline
\end{tabular}

RC: 101075

Disponível em: https://www.nucleodoconhecimento.com.br/arquitetura/acolhimentoas-vitimas 


\begin{tabular}{|c|c|c|c|c|c|c|c|c|c|c|}
\hline & & & & $\begin{array}{l}\text { rend } \\
\text { a }\end{array}$ & $\begin{array}{l}\text { S. } \\
\text { M. }\end{array}$ & $\begin{array}{l}\text { de } \\
2 \\
\text { S. } \\
\text { M. }\end{array}$ & $\begin{array}{l}\text { remuner } \\
\text { ado }\end{array}$ & $\begin{array}{l}\text { trabalho } \\
\text { remuner } \\
\text { ado }\end{array}$ & & \\
\hline $\begin{array}{l}\text { Ter medo do } \\
\text { agressor }\end{array}$ & $\begin{array}{l}71 \\
\%\end{array}$ & $\begin{array}{l}72 \\
\%\end{array}$ & $\begin{array}{l}71 \\
\%\end{array}$ & $77 \%$ & $\begin{array}{l}69 \\
\%\end{array}$ & $\begin{array}{l}73 \\
\%\end{array}$ & $72 \%$ & $71 \%$ & $\begin{array}{l}71 \\
\%\end{array}$ & $\begin{array}{l}72 \\
\%\end{array}$ \\
\hline $\begin{array}{l}\text { Preocupar- } \\
\text { se com a } \\
\text { criação dos } \\
\text { filhos }\end{array}$ & $\begin{array}{l}32 \\
\%\end{array}$ & $\begin{array}{l}33 \\
\%\end{array}$ & $\begin{array}{l}31 \\
\%\end{array}$ & $33 \%$ & $\begin{array}{l}31 \\
\%\end{array}$ & $\begin{array}{l}33 \\
\%\end{array}$ & $30 \%$ & $32 \%$ & $\begin{array}{l}31 \\
\%\end{array}$ & $\begin{array}{l}34 \\
\%\end{array}$ \\
\hline $\begin{array}{l}\text { Depender } \\
\text { financeiram } \\
\text { ente do } \\
\text { agressor }\end{array}$ & $\begin{array}{l}29 \\
\%\end{array}$ & $\begin{array}{l}32 \\
\%\end{array}$ & $\begin{array}{l}27 \\
\%\end{array}$ & $33 \%$ & $\begin{array}{l}24 \\
\%\end{array}$ & $\begin{array}{l}38 \\
\%\end{array}$ & $27 \%$ & $30 \%$ & $\begin{array}{l}29 \\
\%\end{array}$ & $\begin{array}{l}30 \\
\%\end{array}$ \\
\hline $\begin{array}{l}\text { Não existir } \\
\text { punição }\end{array}$ & $\begin{array}{l}25 \\
\%\end{array}$ & $\begin{array}{l}30 \\
\%\end{array}$ & $\begin{array}{l}23 \\
\%\end{array}$ & $25 \%$ & $\begin{array}{l}25 \\
\%\end{array}$ & $\begin{array}{l}25 \\
\%\end{array}$ & $23 \%$ & $27 \%$ & $\begin{array}{l}25 \\
\%\end{array}$ & $\begin{array}{l}24 \\
\%\end{array}$ \\
\hline $\begin{array}{l}\text { Ter } \\
\text { vergonha da } \\
\text { agressão }\end{array}$ & $\begin{array}{l}20 \\
\%\end{array}$ & $\begin{array}{l}23 \\
\%\end{array}$ & $\begin{array}{l}19 \\
\%\end{array}$ & $20 \%$ & $\begin{array}{l}18 \\
\%\end{array}$ & $\begin{array}{l}26 \\
\%\end{array}$ & $18 \%$ & $21 \%$ & $\begin{array}{l}18 \\
\%\end{array}$ & $\begin{array}{l}26 \\
\%\end{array}$ \\
\hline $\begin{array}{l}\text { Acreditar } \\
\text { que seria a } \\
\text { última vez }\end{array}$ & $\begin{array}{l}17 \\
\%\end{array}$ & $\begin{array}{l}16 \\
\%\end{array}$ & $\begin{array}{l}17 \\
\%\end{array}$ & $18 \%$ & $\begin{array}{l}16 \\
\%\end{array}$ & $\begin{array}{l}21 \\
\%\end{array}$ & $14 \%$ & $20 \%$ & $\begin{array}{l}15 \\
\%\end{array}$ & $\begin{array}{l}23 \\
\%\end{array}$ \\
\hline $\begin{array}{l}\text { Não } \\
\text { conhecer } \\
\text { seus } \\
\text { direitos }\end{array}$ & $\begin{array}{l}15 \\
\%\end{array}$ & $\begin{array}{l}16 \\
\%\end{array}$ & $\begin{array}{l}15 \\
\%\end{array}$ & $18 \%$ & $\begin{array}{l}14 \\
\%\end{array}$ & $\begin{array}{l}16 \\
\%\end{array}$ & $16 \%$ & $15 \%$ & $\begin{array}{l}15 \\
\%\end{array}$ & $\begin{array}{l}17 \\
\%\end{array}$ \\
\hline Outros & $2 \%$ & $2 \%$ & $2 \%$ & $3 \%$ & $2 \%$ & $1 \%$ & $2 \%$ & $2 \%$ & $2 \%$ & $2 \%$ \\
\hline $\begin{array}{l}\text { Não sei ou } \\
\text { prefiro não } \\
\text { responder }\end{array}$ & $0 \%$ & $0 \%$ & $0 \%$ & $0 \%$ & $1 \%$ & $0 \%$ & $1 \%$ & $0 \%$ & $0 \%$ & $0 \%$ \\
\hline
\end{tabular}

RC: 101075

Disponível em: https://www.nucleodoconhecimento.com.br/arquitetura/acolhimentoas-vitimas 


\begin{tabular}{|c|c|c|c|c|c|c|c|c|c|c|}
\hline $\begin{array}{l}\text { Base } \\
\text { ponderada }\end{array}$ & $\begin{array}{l}111 \\
6\end{array}$ & $\begin{array}{l}32 \\
6\end{array}$ & 787 & 289 & $\begin{array}{l}61 \\
9\end{array}$ & 196 & 521 & 528 & $\begin{array}{l}85 \\
3\end{array}$ & $\begin{array}{l}26 \\
2\end{array}$ \\
\hline $\begin{array}{l}\text { Número de } \\
\text { respondente } \\
\text { s }\end{array}$ & $\begin{array}{l}111 \\
6\end{array}$ & $\begin{array}{l}29 \\
8\end{array}$ & 817 & 220 & $\begin{array}{l}50 \\
1\end{array}$ & 319 & 432 & 629 & $\begin{array}{l}78 \\
7\end{array}$ & $\begin{array}{l}32 \\
8\end{array}$ \\
\hline
\end{tabular}

Fonte: Adaptado de Senado Federal (2017)

Tabela 2 - O que leva uma mulher a não denunciar a agressão? (Idade e Escolaridade)

\begin{tabular}{|c|c|c|c|c|c|c|c|c|c|c|}
\hline & \multirow[b]{2}{*}{$\begin{array}{l}\text { Tot } \\
\text { al }\end{array}$} & \multicolumn{6}{|c|}{ Idade } & \multicolumn{3}{|c|}{ Escolaridade } \\
\hline & & $\begin{array}{l}\text { De } \\
16 \\
a \\
19 \\
\text { ano } \\
\mathrm{s}\end{array}$ & $\begin{array}{l}\text { De } \\
20 \\
a \\
29 \\
\text { ano } \\
s\end{array}$ & $\begin{array}{l}\text { De } \\
30 \\
a \\
39 \\
\text { ano } \\
\mathrm{s}\end{array}$ & $\begin{array}{l}\text { De } \\
40 \\
a \\
49 \\
\text { ano } \\
s\end{array}$ & $\begin{array}{l}\text { De } \\
50 \\
a \\
59 \\
\text { ano } \\
s\end{array}$ & $\begin{array}{l}60 \\
\text { ano } \\
\mathrm{s} \\
\text { ou } \\
\text { mai } \\
\mathrm{s}\end{array}$ & $\begin{array}{l}\text { Até } \\
\text { ensino } \\
\text { funda- } \\
\text { mental } \\
\text { comple } \\
\text { to }\end{array}$ & $\begin{array}{l}\text { Ensi- } \\
\text { no } \\
\text { médi } \\
\text { o } \\
\text { com- } \\
\text { pleto }\end{array}$ & $\begin{array}{l}\text { Ensi } \\
\text { - no } \\
\text { sup } \\
\text { e- } \\
\text { rior } \\
\text { com } \\
\text { - } \\
\text { plet } \\
\text { o }\end{array}$ \\
\hline $\begin{array}{l}\text { Ter medo do } \\
\text { agressor }\end{array}$ & $71 \%$ & $\begin{array}{l}81 \\
\%\end{array}$ & $\begin{array}{l}74 \\
\%\end{array}$ & $\begin{array}{l}70 \\
\%\end{array}$ & $\begin{array}{l}71 \\
\%\end{array}$ & $\begin{array}{l}71 \\
\%\end{array}$ & $\begin{array}{l}66 \\
\%\end{array}$ & $73 \%$ & $68 \%$ & $75 \%$ \\
\hline $\begin{array}{l}\text { Preocupar-se } \\
\text { com a } \\
\text { criação dos } \\
\text { filhos }\end{array}$ & $32 \%$ & $\begin{array}{l}45 \\
\%\end{array}$ & $\begin{array}{l}33 \\
\%\end{array}$ & $\begin{array}{l}33 \\
\%\end{array}$ & $\begin{array}{l}34 \\
\%\end{array}$ & $\begin{array}{l}22 \\
\%\end{array}$ & $\begin{array}{l}31 \\
\%\end{array}$ & $31 \%$ & $32 \%$ & $34 \%$ \\
\hline $\begin{array}{l}\text { Depender } \\
\text { financeirame } \\
\text { nte do } \\
\text { agressor }\end{array}$ & $29 \%$ & $\begin{array}{l}21 \\
\%\end{array}$ & $\begin{array}{l}27 \\
\%\end{array}$ & $\begin{array}{l}29 \\
\%\end{array}$ & $\begin{array}{l}35 \\
\%\end{array}$ & $\begin{array}{l}25 \\
\%\end{array}$ & $\begin{array}{l}31 \\
\%\end{array}$ & $20 \%$ & $33 \%$ & $47 \%$ \\
\hline
\end{tabular}




\begin{tabular}{|c|c|c|c|c|c|c|c|c|c|c|}
\hline $\begin{array}{l}\text { Não existir } \\
\text { punição }\end{array}$ & $25 \%$ & $\begin{array}{l}15 \\
\%\end{array}$ & $\begin{array}{l}25 \\
\%\end{array}$ & $\begin{array}{l}28 \\
\%\end{array}$ & $\begin{array}{l}29 \\
\%\end{array}$ & $\begin{array}{l}23 \\
\%\end{array}$ & $\begin{array}{l}21 \\
\%\end{array}$ & $17 \%$ & $33 \%$ & $30 \%$ \\
\hline $\begin{array}{l}\text { Ter vergonha } \\
\text { da agressão }\end{array}$ & $20 \%$ & $\begin{array}{l}27 \\
\%\end{array}$ & $\begin{array}{l}16 \\
\%\end{array}$ & $\begin{array}{l}22 \\
\%\end{array}$ & $\begin{array}{l}22 \\
\%\end{array}$ & $\begin{array}{l}21 \\
\%\end{array}$ & $\begin{array}{l}16 \\
\%\end{array}$ & $16 \%$ & $20 \%$ & $33 \%$ \\
\hline $\begin{array}{l}\text { Acreditar que } \\
\text { seria a última } \\
\text { vez }\end{array}$ & $17 \%$ & $\begin{array}{l}34 \\
\%\end{array}$ & $\begin{array}{l}20 \\
\%\end{array}$ & $\begin{array}{l}21 \\
\%\end{array}$ & $\begin{array}{l}11 \\
\%\end{array}$ & $\begin{array}{l}13 \\
\%\end{array}$ & $\begin{array}{l}10 \\
\%\end{array}$ & $14 \%$ & $17 \%$ & $27 \%$ \\
\hline $\begin{array}{l}\text { Não } \\
\text { conhecer } \\
\text { seus direitos }\end{array}$ & $15 \%$ & $\begin{array}{l}17 \\
\%\end{array}$ & $\begin{array}{l}15 \\
\%\end{array}$ & $\begin{array}{l}15 \\
\%\end{array}$ & $\begin{array}{l}15 \\
\%\end{array}$ & $\begin{array}{l}18 \\
\%\end{array}$ & $\begin{array}{l}13 \\
\%\end{array}$ & $14 \%$ & $15 \%$ & $19 \%$ \\
\hline Outros & $2 \%$ & $2 \%$ & $1 \%$ & $3 \%$ & $3 \%$ & $2 \%$ & $1 \%$ & $2 \%$ & $2 \%$ & $2 \%$ \\
\hline $\begin{array}{l}\text { Não sei ou } \\
\text { prefiro não } \\
\text { responder }\end{array}$ & $0 \%$ & $0 \%$ & $0 \%$ & $0 \%$ & $1 \%$ & $0 \%$ & $1 \%$ & $0 \%$ & $0 \%$ & $1 \%$ \\
\hline $\begin{array}{l}\text { Base } \\
\text { ponderada }\end{array}$ & $\begin{array}{l}111 \\
6\end{array}$ & 76 & 239 & 261 & 177 & 182 & 181 & 542 & 410 & 164 \\
\hline $\begin{array}{l}\text { Número de } \\
\text { respondentes }\end{array}$ & $\begin{array}{l}111 \\
6\end{array}$ & 59 & 280 & 289 & 200 & 150 & 138 & 332 & 492 & 292 \\
\hline
\end{tabular}

Fonte: Adaptado de Senado Federal (2017)

Tabela 3 - O que leva uma mulher a não denunciar a agressão? (Região e cor/raça)

\begin{tabular}{|c|c|c|c|c|c|c|c|c|c|c|}
\hline & \multirow[b]{2}{*}{$\begin{array}{l}\text { Tot } \\
\text { al }\end{array}$} & \multicolumn{5}{|c|}{ Região } & \multicolumn{4}{|c|}{ Cor/Raça } \\
\hline & & $\begin{array}{l}\text { Centr } \\
\text { o- } \\
\text { Oest } \\
\text { e }\end{array}$ & $\begin{array}{l}\text { Norde } \\
\text { ste }\end{array}$ & $\begin{array}{l}\text { Nort } \\
\mathrm{e}\end{array}$ & $\begin{array}{l}\text { Sudes } \\
\text { te }\end{array}$ & Sul & $\begin{array}{l}\text { Bran } \\
\text { ca }\end{array}$ & $\begin{array}{l}\text { Pret } \\
a\end{array}$ & $\begin{array}{l}\text { Par } \\
\text { da }\end{array}$ & $\begin{array}{l}\text { Outr } \\
\text { as }\end{array}$ \\
\hline $\begin{array}{l}\text { Ter medo do } \\
\text { agressor }\end{array}$ & $\begin{array}{l}71 \\
\%\end{array}$ & $72 \%$ & $71 \%$ & $\begin{array}{l}75 \\
\%\end{array}$ & $71 \%$ & $\begin{array}{l}71 \\
\%\end{array}$ & $72 \%$ & $\begin{array}{l}74 \\
\%\end{array}$ & $70 \%$ & $68 \%$ \\
\hline Preocupar- & 32 & $48 \%$ & $30 \%$ & 31 & $30 \%$ & 32 & $32 \%$ & 24 & $35 \%$ & $29 \%$ \\
\hline
\end{tabular}

RC: 101075

Disponível em: https://www.nucleodoconhecimento.com.br/arquitetura/acolhimentoas-vitimas 


\begin{tabular}{|c|c|c|c|c|c|c|c|c|c|c|}
\hline $\begin{array}{l}\text { se com a } \\
\text { criação dos } \\
\text { filhos }\end{array}$ & $\%$ & & & $\%$ & & $\%$ & & $\%$ & & \\
\hline $\begin{array}{l}\text { Depender } \\
\text { financeiram } \\
\text { ente do } \\
\text { agressor }\end{array}$ & $\begin{array}{l}29 \\
\%\end{array}$ & $23 \%$ & $24 \%$ & $\begin{array}{l}28 \\
\%\end{array}$ & $33 \%$ & $\begin{array}{l}26 \\
\%\end{array}$ & $29 \%$ & $\begin{array}{l}32 \\
\%\end{array}$ & $28 \%$ & $29 \%$ \\
\hline $\begin{array}{l}\text { Não existir } \\
\text { punição }\end{array}$ & $\begin{array}{l}25 \\
\%\end{array}$ & $25 \%$ & $21 \%$ & $\begin{array}{l}16 \\
\%\end{array}$ & $29 \%$ & $\begin{array}{l}22 \\
\%\end{array}$ & $23 \%$ & $\begin{array}{l}24 \\
\%\end{array}$ & $27 \%$ & $35 \%$ \\
\hline $\begin{array}{l}\text { Ter } \\
\text { vergonha da } \\
\text { agressão }\end{array}$ & $\begin{array}{l}20 \\
\%\end{array}$ & $21 \%$ & $14 \%$ & $\begin{array}{l}20 \\
\%\end{array}$ & $23 \%$ & $\begin{array}{l}18 \\
\%\end{array}$ & $22 \%$ & $\begin{array}{l}21 \\
\%\end{array}$ & $17 \%$ & $21 \%$ \\
\hline $\begin{array}{l}\text { Acreditar } \\
\text { que seria a } \\
\text { última vez }\end{array}$ & $\begin{array}{l}17 \\
\%\end{array}$ & $23 \%$ & $15 \%$ & $\begin{array}{l}17 \\
\%\end{array}$ & $18 \%$ & $\begin{array}{l}14 \\
\%\end{array}$ & $17 \%$ & $\begin{array}{l}15 \\
\%\end{array}$ & $15 \%$ & $12 \%$ \\
\hline $\begin{array}{l}\text { Não } \\
\text { conhecer } \\
\text { seus } \\
\text { direitos }\end{array}$ & $\begin{array}{l}15 \\
\%\end{array}$ & $21 \%$ & $15 \%$ & $\begin{array}{l}10 \\
\%\end{array}$ & $16 \%$ & $\begin{array}{l}14 \\
\%\end{array}$ & $17 \%$ & $\begin{array}{l}15 \\
\%\end{array}$ & $15 \%$ & $12 \%$ \\
\hline Outros & $2 \%$ & $1 \%$ & $1 \%$ & $1 \%$ & $3 \%$ & $2 \%$ & $3 \%$ & $2 \%$ & $2 \%$ & $0 \%$ \\
\hline $\begin{array}{l}\text { Não sei ou } \\
\text { prefiro não } \\
\text { responder }\end{array}$ & $0 \%$ & $0 \%$ & $1 \%$ & $0 \%$ & $0 \%$ & $0 \%$ & $0 \%$ & $0 \%$ & $0 \%$ & $0 \%$ \\
\hline $\begin{array}{l}\text { Base } \\
\text { ponderada }\end{array}$ & $\begin{array}{l}111 \\
6\end{array}$ & 86 & 254 & 67 & 542 & $\begin{array}{l}16 \\
7\end{array}$ & 488 & 116 & 426 & 50 \\
\hline $\begin{array}{l}\text { Número de } \\
\text { respondente } \\
\text { s }\end{array}$ & $\begin{array}{l}111 \\
6\end{array}$ & 87 & 311 & 102 & 457 & $\begin{array}{l}15 \\
9\end{array}$ & 489 & 118 & 433 & 45 \\
\hline
\end{tabular}

Fonte: Adaptado de Senado Federal (2017)

RC: 101075

Disponível em: https://www.nucleodoconhecimento.com.br/arquitetura/acolhimentoas-vitimas 
A Lei Maria da Penha classifica a violência psicológica também como um dos tipos de abusos, podendo ocorrer mediante ameaças, constrangimentos, humilhação, entre outros tipos de conduta que prejudique e controle, conforme dito pela Revista Época (2019). Serão apresentados a seguir gráficos que ilustram essas informações. O gráfico 1 apresenta o crescimento dos números de vítimas de violência psicológica, passando de 2.629 notificações no ano de 2009 para 18.219 em 2016.

Gráfico 1 - Violência psicológica por cônjuge ou namorado

\section{Total de notificaçöes}

18219

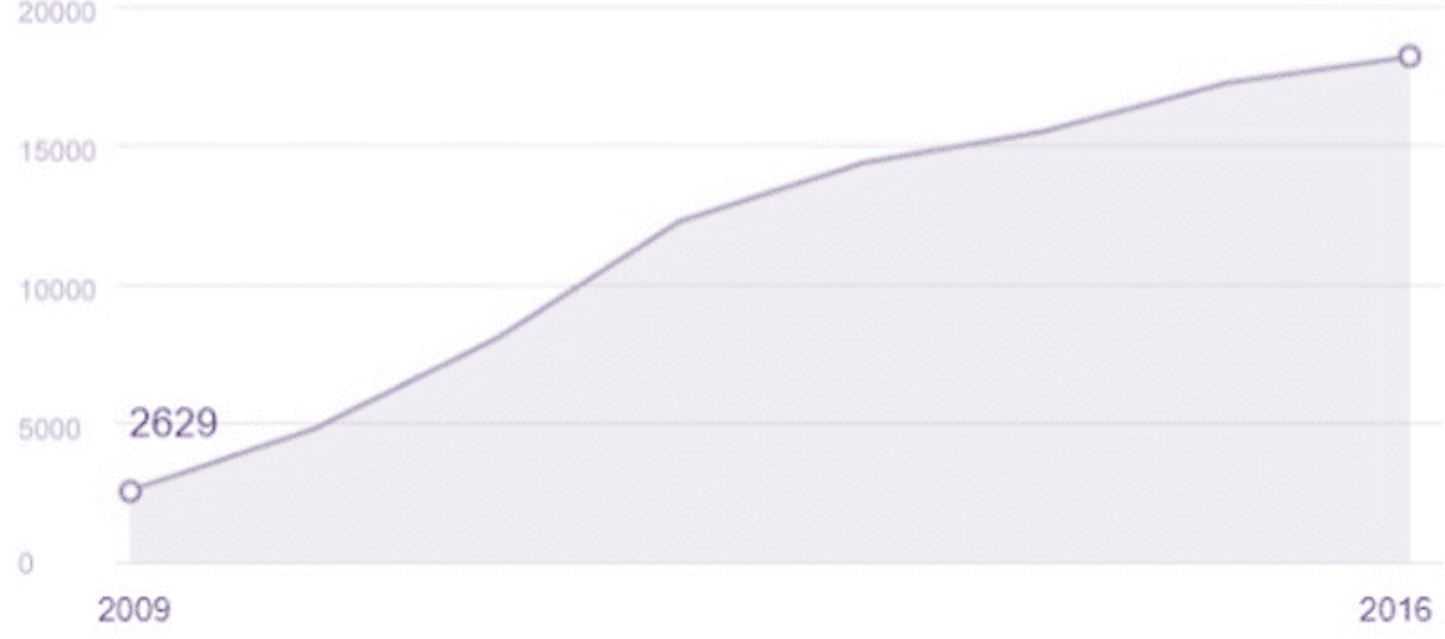

Fonte: Adaptado de Ministério da Saúde/SVS - Sistema de Informação de Agravos de Notificação - Sinan Net (2016).

De acordo com o gráfico 2, desenvolvido pelo Ministério da saúde, com dados do Sistema de Informação de Agravos de Notificação, a violência física (espancamento, sufocamento, apertar braços, lesões com objetos cortantes, tortura, ferimentos por queimaduras, entre outros) por namorados ou cônjuges quadriplicou entre os anos de 2009 e 2016 no Brasil, de 4.339 para 33.961 . 
Gráfico 2 - Violência física por cônjuge ou namorado

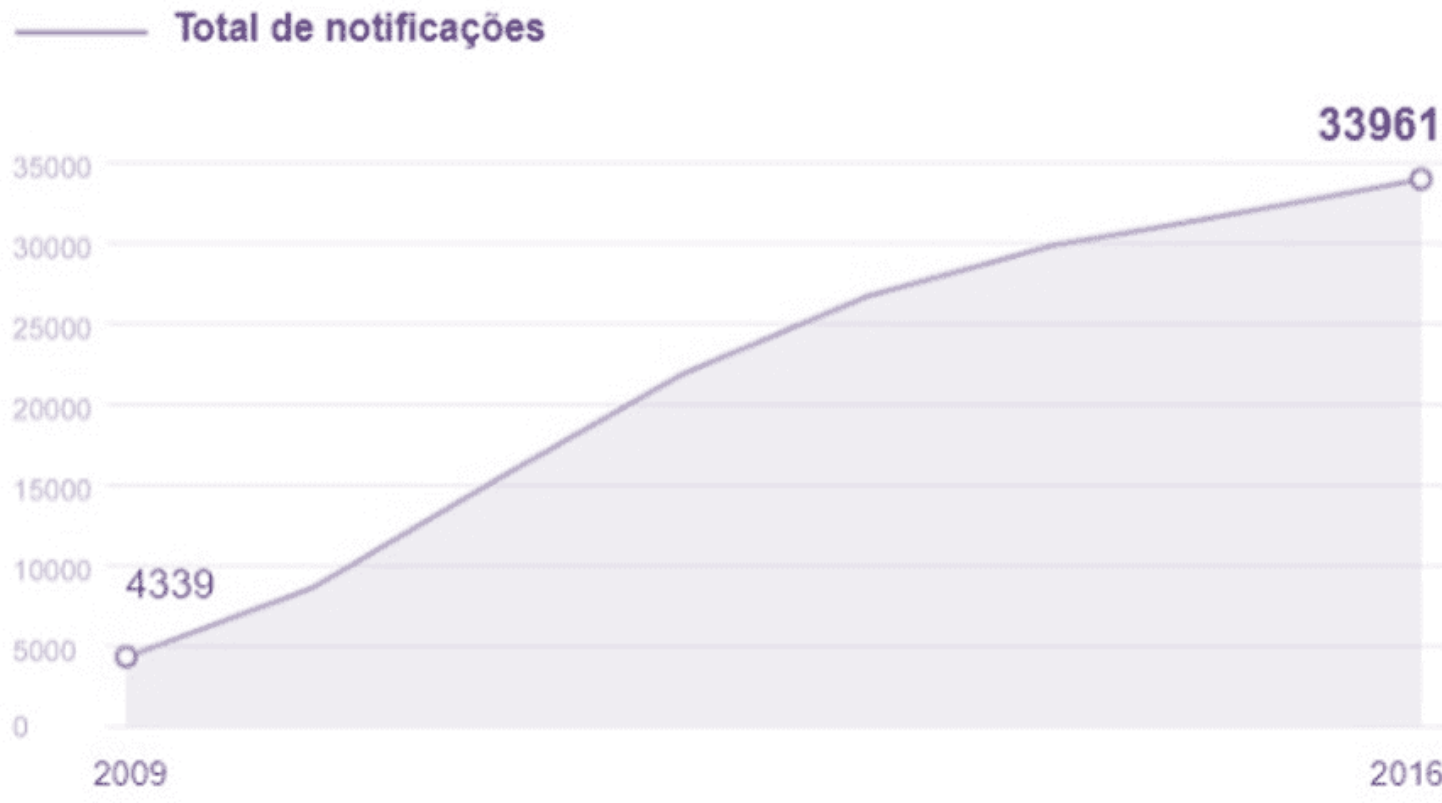

Fonte: Adaptado de Ministério da Saúde/SVS - Sistema de Informação de Agravos de Notificação - Sinan Net (2016).

Assim como nos gráficos anteriores, as notificações de violência por arma de fogo aumentaram significativamente, quase quadruplicaram desde o ano do início da pesquisa, de 1.120 casos para 4.209 em sete anos (gráfico 3).

RC: 101075

Disponível em: https://www.nucleodoconhecimento.com.br/arquitetura/acolhimentoas-vitimas 
Gráfico 3 - Violência por arma de fogo contra mulher

\section{Total de notificaçōes}

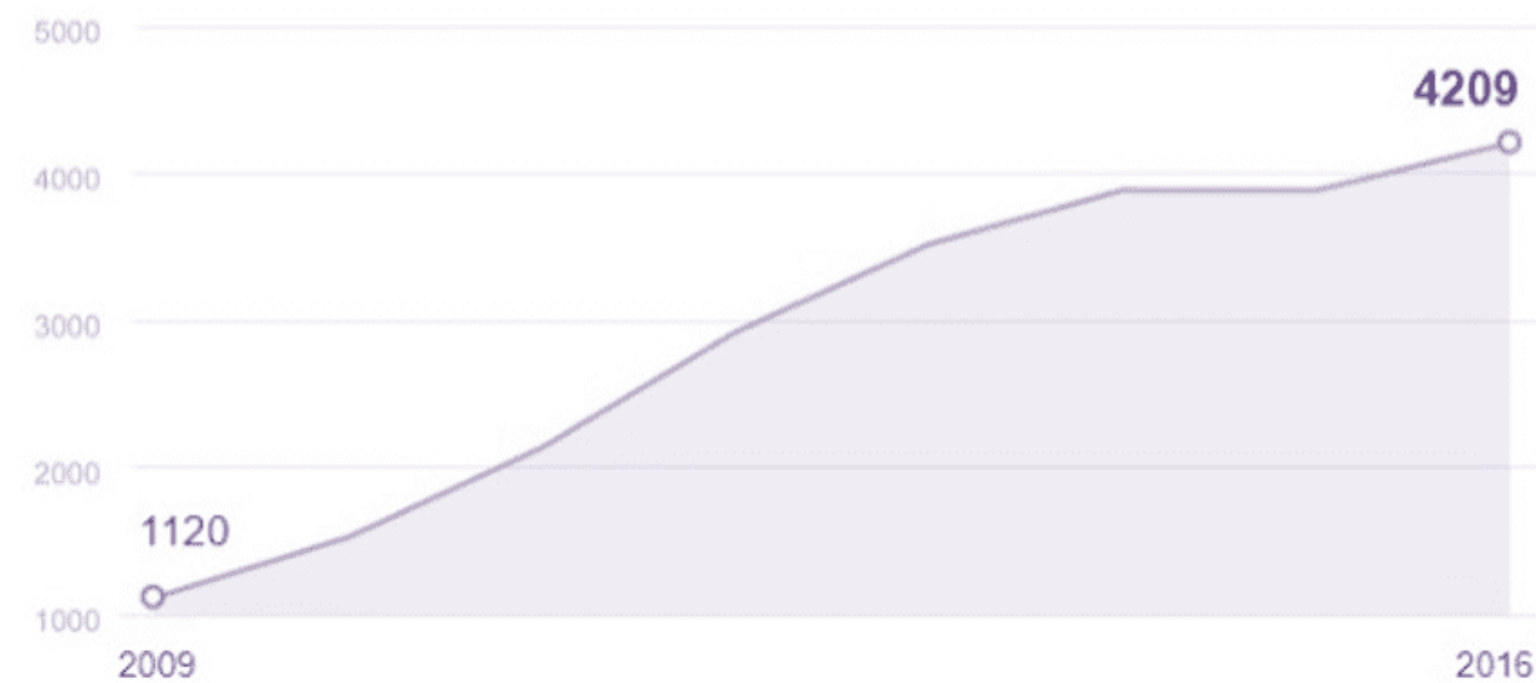

Fonte: Adaptado de Ministério da Saúde/SVS - Sistema de Informação de Agravos de Notificação - Sinan Net (2016).

As notificações de estupros por cônjuges ou namorados, cresceu sete vezes (de 73 para 890) de 2009 a 2016 (gráfico 4), ano em que a Lei 10.015 reconheceu o estupro marital, o qual se configura quando há ocorrência de infringência sexual contra um dos parceiros, mesmo dentro de um relacionamento, de acordo com o art. 213 do Código Penal, segundo Nunes (2015), antes disso, havia a possibilidade de que o estuprador não fosse punido caso fosse cônjuge da vítima.

RC: 101075

Disponível em: https://www.nucleodoconhecimento.com.br/arquitetura/acolhimentoas-vitimas 
Gráfico 4 - Estupros por cônjuges ou namorado

\section{Total de notificaçōes}

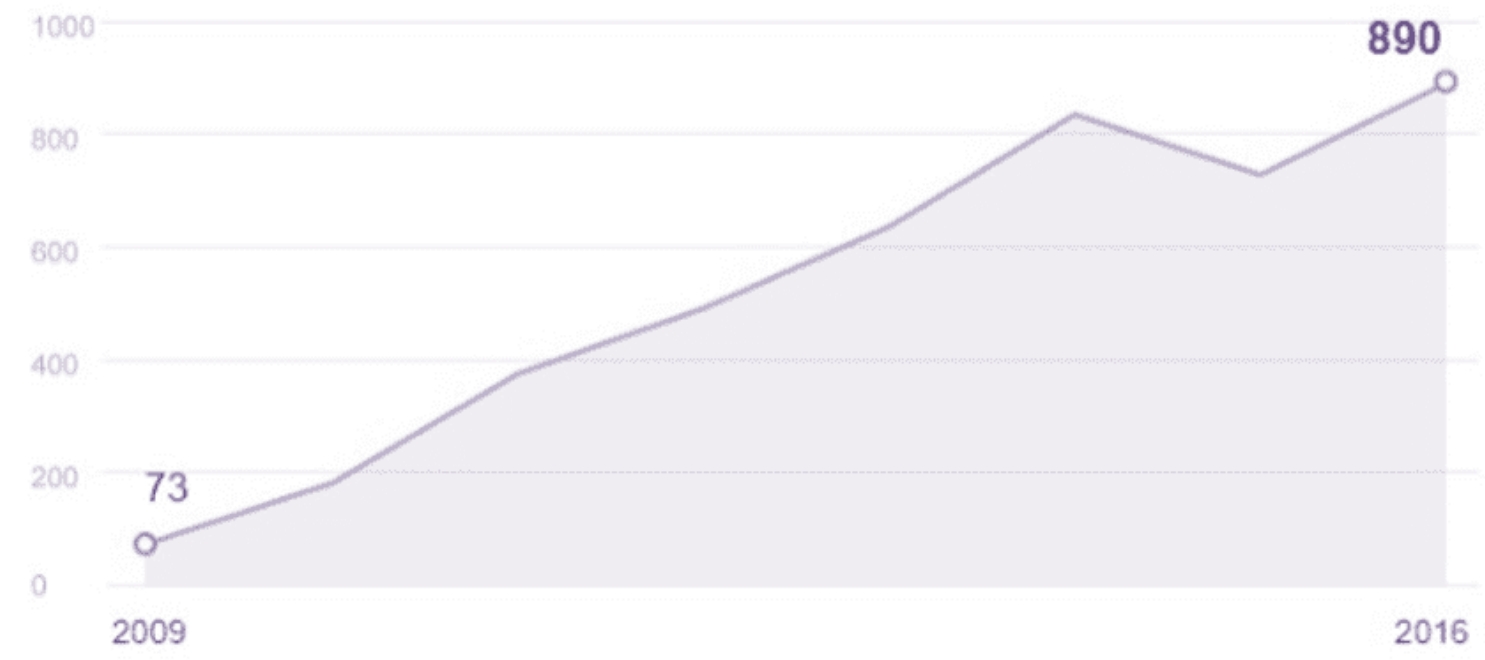

Fonte: Adaptado de Ministério da Saúde/SVS - Sistema de Informação de Agravos de Notificação - Sinan Net (2016).

\subsubsection{O AUXÍLIO DAS CASAS-ABRIGO EXISTENTES NO BRASIL}

Segundo o Conselho Nacional de Justiça (2018), as Casas-Abrigo são lugares nos quais recebe-se mulheres que sofrem ameaças ou são vítimas de violência doméstica, onde abrigam-se durante determinado período, recebendo 0 apoio necessário para que consigam estabilidade e condições de retomarem a vida. $\mathrm{O}$ endereço dessas casas é sigiloso por motivos de segurança das mulheres e de seus filhos, que também recebem esse tratamento e auxílio. Os abrigos possuem regras de convivência para serem seguidas, para o bem-estar de todos os que lá se refugiam. Algumas dessas casas amparam e acolhem entre 5 a 10 mulheres com seus filhos, mas há, também, lugares que esse número aumenta, funcionando como uma espécie de albergue.

A primeira Casa Abrigo do País foi fundada em 1986, em São Paulo (Centro de Convivência para Mulheres Vítimas de Violência Doméstica/ Convida). Em 1992 foram criadas as Casas-Abrigo Viva

RC: 101075

Disponível em: https://www.nucleodoconhecimento.com.br/arquitetura/acolhimentoas-vitimas 
Maria (Rio Grande do Sul) e a Casa do Caminho (Ceará). O Distrito Federal acolheu a primeira casa abrigo no ano de 1996. Segundo dados da Secretaria de Políticas para as Mulheres, havia um total de 72 Casas- Abrigo no país em 2011 (SENADO FEDERAL, 2016).

$\mathrm{Na}$ informação a seguir, pode-se identificar as Casas-Abrigo existentes no Brasil no ano de 2013 (Gráfico 5).

Gráfico 5 - Oferta de serviços especializados de proteção e acolhimento a mulheres agredidas é maior em grandes cidades
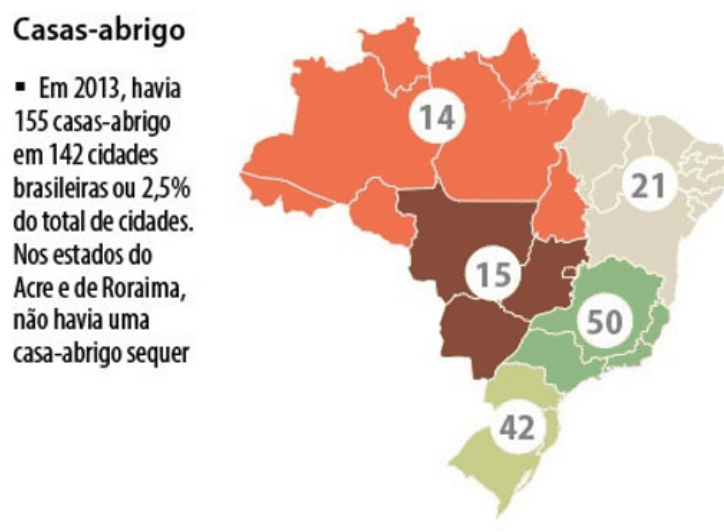

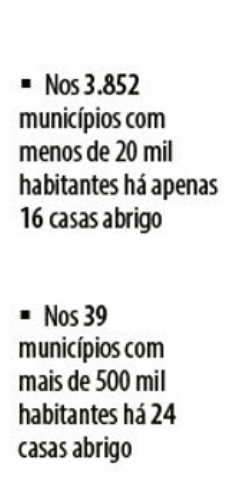

Deam

- Poucos municípios têm delegacias especializadas no atendimento à mulher (Deam) e a expansão é lenta

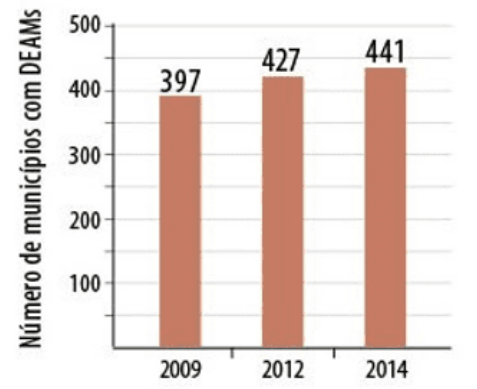

\section{Serviços especializados}

Percentual de municípios com serviços especializados de gestão municipal para mulheres em situação de violência, segundo o tamanho da população:

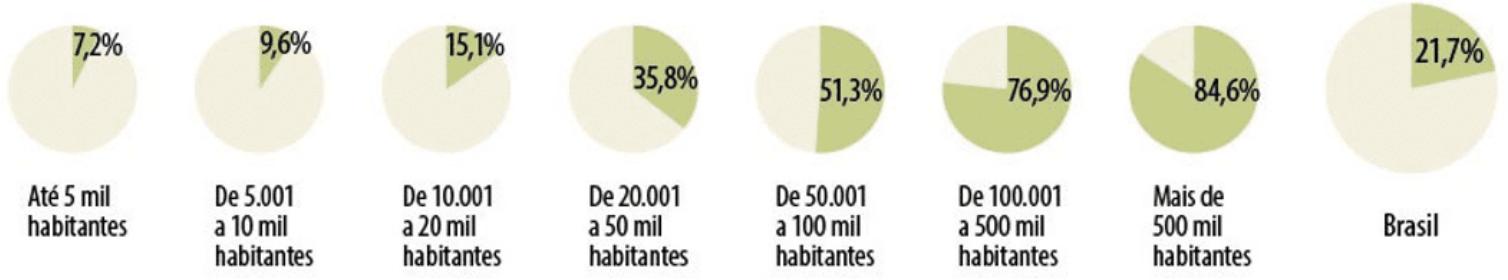

Fonte: Pesquisa de Informações básicas Municipais (Munic), IBGE (2013).

Apenas 2,5\% das cidades do País apresentam esses refúgios para as mulheres, totalizando 155 unidades em 142 cidades, isto é, 97,5\% das cidades não têm disponível a oferta desse tipo de suporte, segundo levantamento realizado pelo IBGE (2013) revelando, através da matéria disponibilizada no site O Globo: Sociedade (2019) que não houve progresso no acolhimento às vítimas de violência doméstica.

RC: 101075

Disponível em: https://www.nucleodoconhecimento.com.br/arquitetura/acolhimentoas-vitimas 


\subsection{ARQUITETURA DE REFÚGIO}

Tem-se a arquitetura emergencial de refúgio para vítimas de violência doméstica (Casa Abrigo Lar da Mulher e Casa Abrigo Canto de Dália em estudo no artigo), para imigrantes e refugiados em geral, de desastres naturais, de guerras, entre outros. Existem também algumas casas de acolhimento à população LGBTQI+ (lésbicas, gays, bissexuais, transexuais, queer, intersexuais e o "+" engloba todos os outros tipos de orientação sexual), como por exemplo, no Brasil encontra-se a Casa Nem, com três unidades na cidade do Rio de Janeiro, a Casa 1 e o Centro de Acolhida Florescer, ambas em São Paulo, em conformidade com a notícia disponibilizada no site Projeto Colabora (2019).

\subsubsection{CASA ABRIGO LAR DA MULHER (ASSISTÊNCIA SOCIAL, PSICOLÓGICA E JURÍDICA PARA MULHERES DE VIOLÊNCIA DOMÉSTICA)}

Com o objetivo de proteção e fortalecimento das mulheres, a Casa Abrigo Lar da Mulher é localizada no Rio de Janeiro (RJ), no bairro Laranjeiras e teve sua criação no ano de 2007, concedendo assistência psicológica, social, hospitalar e jurídica (Figura 1). O trabalho é elaborado e preparado para que as abrigadas compreendam os seus direitos, evoluam a consciência acerca de relacionamentos afetivos saudáveis e recuperem suas vidas de forma segura e inseridas no mercado de trabalho (CASA ABRIGO LAR DA MULHER, 2014). 
Figura 1 - Casa Abrigo Lar da Mulher

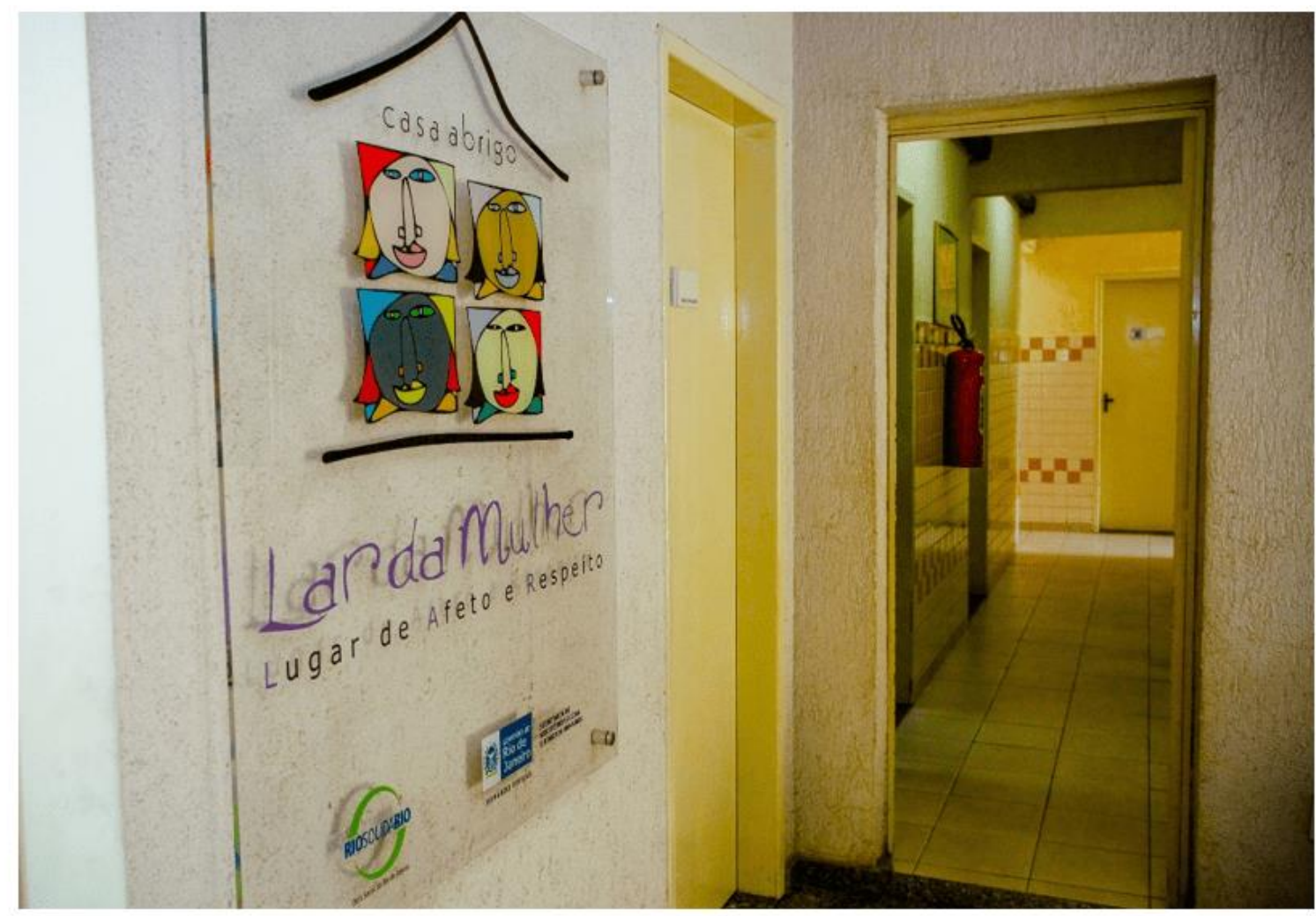

Fonte: Riosolidário - transformando realidades, Casa Abrigo Lar da Mulher (2014).

O Lar da Mulher fica em um local sigiloso no município do Rio de Janeiro e funciona 24 horas por dia (Figura 2), como residência temporária e pode acomodar 60 pessoas, entre mulheres e crianças. A casa possui 15 quartos, salas de atividades e uma creche, apresentando uma área de 1.300 metros quadrados. Grupos reflexivos, atividades recreativas e atividades de relaxamento podem auxiliar essas mulheres a reconstruir suas relações familiares e de amizade, que geralmente são rompidas pelo medo dos agressores. Elas são encaminhadas por centros de referência para mulheres, abrigos, ordens judiciais ou agências de aplicação da lei (delegacias). Desde a sua criação, a Casa acolheu 1.855 pessoas, sendo 713 mulheres e 1.142 crianças (CASA ABRIGO LAR DA MULHER, 2014). 
Figura 2 - Casa Abrigo Lar da Mulher

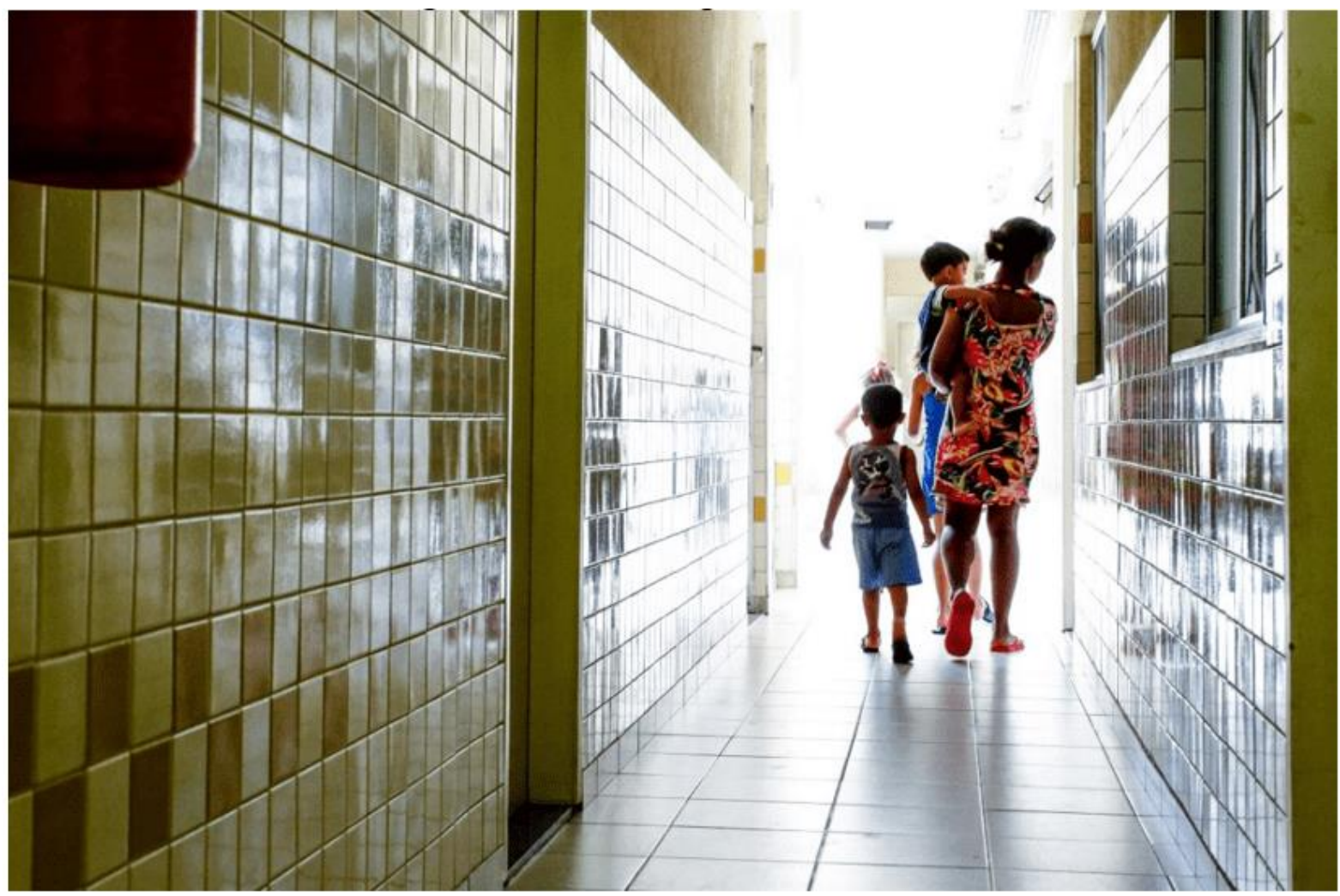

Fonte: Riosolidário - transformando realidades, Casa Abrigo Lar da Mulher (2014).

\subsubsection{CASA ABRIGO CANTO DE DÁLIA}

A Casa Abrigo Canto de Dália é um lar essencialmente temporário e (Tabela 4), com serviço governamental que integra Secretaria de Políticas para as Mulheres de Londrina e teve a criação em junho de 2004. A Casa funciona de forma ininterrupta o atendimento às mulheres em risco de morte e em situação de violência doméstica no geral, acompanhadas ou não dos filhos menores de 18 anos (Tabela 5), moradoras da cidade de Londrina-PR (LONDRINA, 2016).

Tabela 4 - Tempo de permanência no abrigo

\begin{tabular}{|l|l|l|l|}
\hline $\begin{array}{l}\text { Tempo } \\
\text { Abrigo }\end{array}$ & de & Total & $\%$ \\
\hline
\end{tabular}

RC: 101075

Disponível em: https://www.nucleodoconhecimento.com.br/arquitetura/acolhimentoas-vitimas 


\begin{tabular}{|c|c|c|}
\hline Entre 5 a 15 dias & 17 & $31,48 \%$ \\
\hline Até 5 dias & 14 & $25,93 \%$ \\
\hline $\begin{array}{llll}\text { Entre } & 15 \text { a } & 30 \\
\text { dias } & & & \end{array}$ & 10 & $18,52 \%$ \\
\hline Ignorado & 5 & $9,26 \%$ \\
\hline $\begin{array}{llll}\text { Entre } & 30 & \text { a } & 45 \\
\text { dias } & & & \end{array}$ & 3 & $5,56 \%$ \\
\hline 2 meses & 2 & $3,70 \%$ \\
\hline 3 meses & 2 & $3,70 \%$ \\
\hline 4 meses & 1 & $1,85 \%$ \\
\hline
\end{tabular}

Fonte: Adaptado de Cássia Maria Carloto e Vanusa Ferreira Calão, adaptado de Casa de Apoio "Canto de Dália" /SMM/PML (2005).

Tabela 5 - Número de filhos

\begin{tabular}{|l|l|l|}
\hline № de filhos & Total & $\%$ \\
\hline $\mathbf{1}$ & 15 & $27,78 \%$ \\
\hline $\mathbf{2}$ & 15 & $27,78 \%$ \\
\hline $\mathbf{3}$ & 11 & $20,37 \%$ \\
\hline $\mathbf{4}$ & 5 & $9,26 \%$ \\
\hline $\mathbf{5}$ & 5 & $9,26 \%$ \\
\hline $\mathbf{0}$ & 1 & $1,85 \%$ \\
\hline $\mathbf{8}$ & 1 & $1,85 \%$ \\
\hline $\mathbf{1 1}$ & 1 & $1,85 \%$ \\
\hline
\end{tabular}

Fonte: Adaptado de Cássia Maria Carloto e Vanusa Ferreira Calão, adaptado de Casa de Apoio "Canto de Dália" /SMM/PML (2005).

A função deste serviço é garantir a segurança e proteção das mulheres e de seus filhos; implementar serviços voltados para a segurança, educação e saúde; indicar parcerias com redes de atendimento para ajudar mulheres que sofreram violência

RC: 101075

Disponível em: https://www.nucleodoconhecimento.com.br/arquitetura/acolhimentoas-vitimas 
doméstica; e fornecer assistência psicossocial e educacional para aumentar a autoestima da mulher e de seus filhos, resgatar vínculos familiares, sociais e comunitários, para que essas mulheres possam escapar da violência vivenciada, e utilizar as medidas de proteção previstas na Lei Maria da Penha como instituição legal. Existem alguns mecanismos de gestão, como reuniões administrativas, reuniões departamentais, discussão de casos com a rede de serviços, reuniões com os abrigados, atendimento pessoal, seminários sobre temas diversos, entre outros (LONDRINA, 2016).

[...] eu tinha medo de ir na delegacia procurar ajuda. Assim, se ele ficasse sabendo poderia ser mais agressivo. Fiquei sabendo pelos outros que o CAM dava toda a assistência, por uma entrevista na televisão, aí eu procurei. Peguei num telefone e liguei. Liguei primeiro no CAM e depois fui na delegacia. (ANA, 31 anos).

Em 2014, 44 mulheres em situação de violência e risco de morte foram abrigadas, com seus filhos e filhas, totalizando 63 crianças e adolescentes. No ano anterior, 2013, foram 38 mulheres e 56 crianças e adolescentes. No local, as mulheres e crianças recebem acompanhamento médico, psicológico, de enfermagem, assistentes sociais, além de segurança feita pela Guarda Municipal. Há também equipes de trabalhos para cozinha, com nutricionista e serviços de limpeza (BONDE NEWS, 2015).

\section{LOCALIDADE}

\subsection{MUNICÍPIO DE JUIZ DE FORA - MG}

A localidade sugerida para o projeto do Centro de apoio é na cidade de Juiz de Fora, Minas Gerais. Sua população foi estimada pelo Instituto Brasileiro de Geografia e Estatística (IBGE) em 564310 habitantes em 2018, sendo o quarto município mais populoso do estado e o $36^{\circ}$ do Brasil. A cidade ocupa uma área de $1429,875 \mathrm{~km}^{2}$, sendo $317,740 \mathrm{~km}^{2}$ em perímetro urbano.

A localidade escolhida se deu devido à região da Zona da Mata ser a terceira com o maior quantitativo de registros de violência doméstica, conforme a Sesp, Secretaria de Estado de Segurança Pública (2018), sendo que, em matéria disponibilizada no 
site do G1 (2019), de acordo com a Delegacia Especializada no Atendimento à Mulher (Deam), a cidade de Juiz de Fora recebe, por dia, aproximadamente 20 denúncias de violência pelas mulheres.

No ano de 2018, segundo conteúdo exposto pelo Tribuna de Minas (2018), os pedidos de medidas protetivas de acordo com a Lei Maria da Penha na cidade de Juiz de Fora, chegou a 1.056 casos. O gráfico 6 aponta o total de ocorrências na Casa da Mulher de Juiz de Fora entre os anos de 2013 e 2018, divido entre as tipologias de agressão.

Gráfico 6 - atendimentos realizados pela CMJF entre 29/05/2013 e 31/08/2018, categorizados por quantidades totais/ano e por tipos de agressão totais durante todo o período informado

\section{ATENDDIMENTOS CASA DA MULHER - JUIZ DE FORA $2013-2018$}

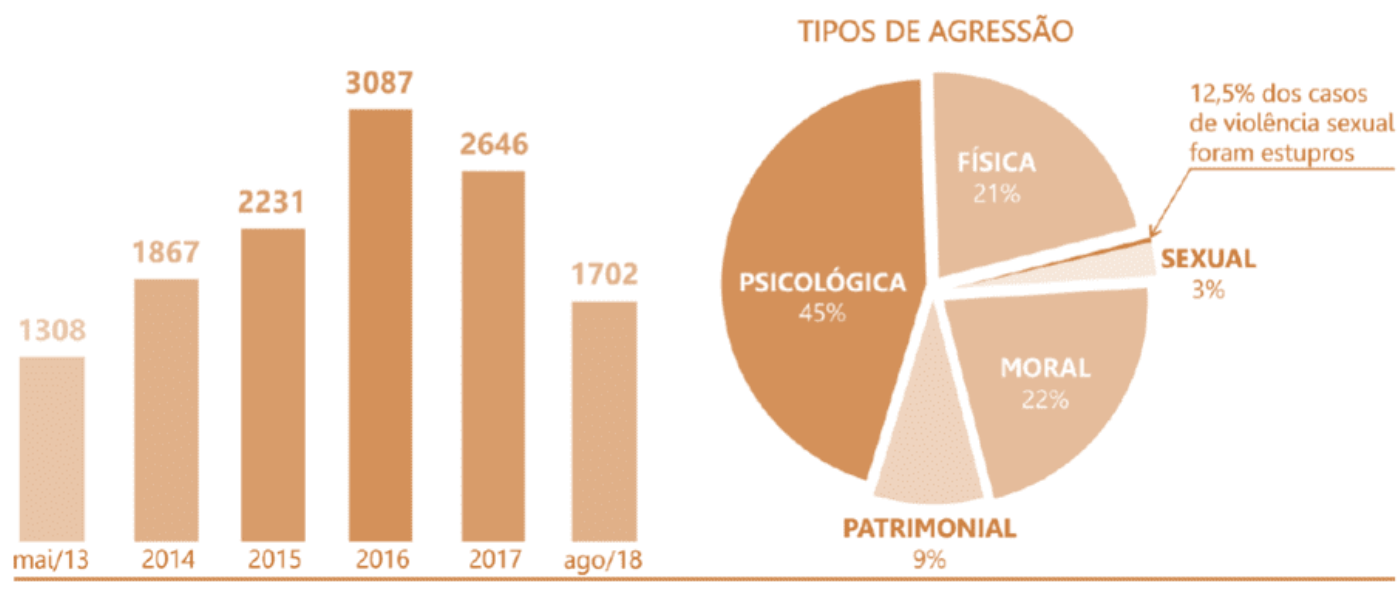

Fonte: Adaptado de Relatório CMJF, elaborado por Glaucy Hellen Herdy Ferreira Gomes (2018).

\subsection{BAIRRO CENTRO}

Um dado importante a ser analisado sobre a violência doméstica, oferecido pela Casa da Mulher de Juiz de Fora (CMJF), é a origem das mulheres por regiões e por bairro na cidade de Juiz de Fora. O mapeamento (figura 3) realizado pela Arquiteta 
Glaucy Hellen Herdy Ferreira Gomes (2018), aponta essas notificações de ocorrências.

Figura 3 - Mapas da origem das mulheres assistidas pela Casa da Mulher de Juiz de Fora no $1^{\circ}$ semestre de 2018 , por hectare da região
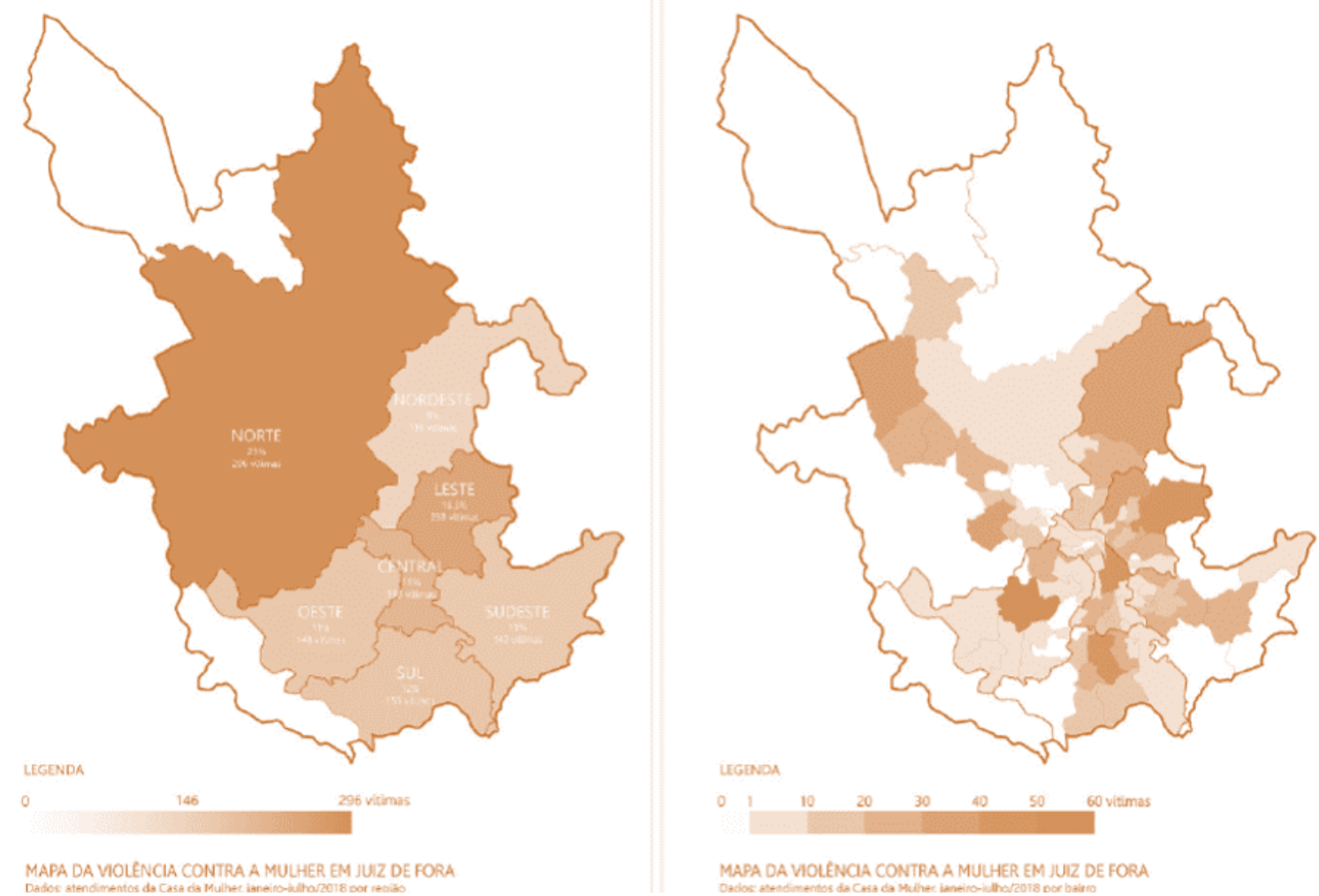

Fonte: Adaptado de Relatório CMJF, elaborado por Glaucy Hellen Herdy Ferreira Gomes (2018).

De acordo com o mapeamento mostrado, a região Norte de Juiz de Fora apresenta um total de 296 vítimas, com $23 \%$ de todas as mulheres acolhidas pela Casa da Mulher. A segunda região com o maior número de vítimas é a Leste, com 238, o equivalente a $18,5 \%$, porém no segundo mapa acima, as pesquisas dos quantitativos por cada bairro, indica números preocupantes localizados nas regiões Central, apresentando aproximadamente 190 ocorrências, Oeste, com 150 e Sul, contabilizando 230 casos. 
Em conformidade com as necessidades das mulheres vítimas de violência doméstica, de acordo com as regiões e bairros da cidade de Juiz de Fora, a região central é a melhor localidade, visto que além de apresentar números alarmantes de casos, a mesma faz conexão com as demais regiões que apresentam maior número de ocorrências, a fim de tornar acessível e visível à todas as mulheres.

\subsection{LOCALIZAÇÃO}

De acordo com o texto acima, a localização de grande potencial para futuros projetos arquitetônicos de refúgio para as mulheres, encontra-se no centro da cidade de Juiz de Fora, a fim de atender toda a cidade, possuindo uma área de aproximadamente 748 metros quadrados (figura 4) e inserida na rua Barão de São João Nepomuceno, próxima à avenidas principais, sendo ela de mão única, com acessos através da Avenida Independência e rua Batista de Oliveira, apresentando fluxo médio de veículos e pedestres. Está situada entre a Zona Comercial 1 e Zona Comercial 2 (figura 5).

Figura 4 - Mapa de situação do terreno

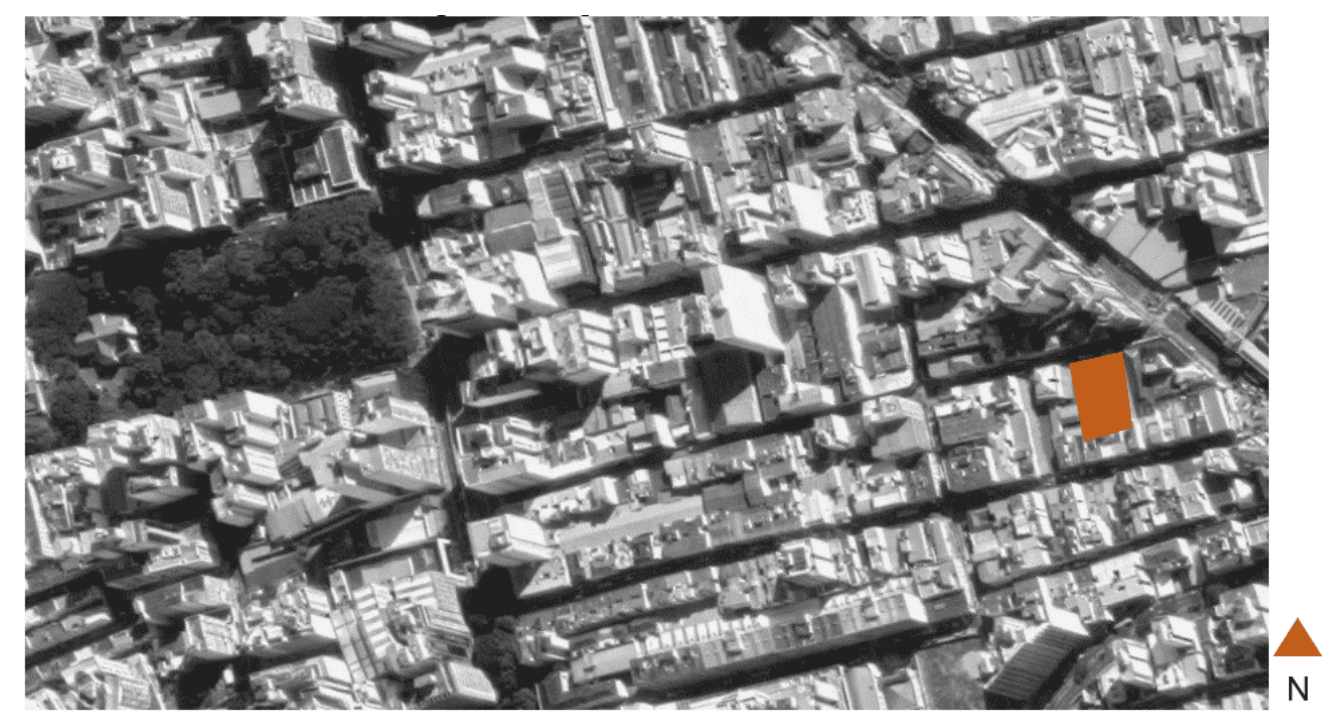

Fonte: Google Maps (2019).

RC: 101075

Disponível em: https://www.nucleodoconhecimento.com.br/arquitetura/acolhimentoas-vitimas 
Figura 5 - Mapa de zoneamento

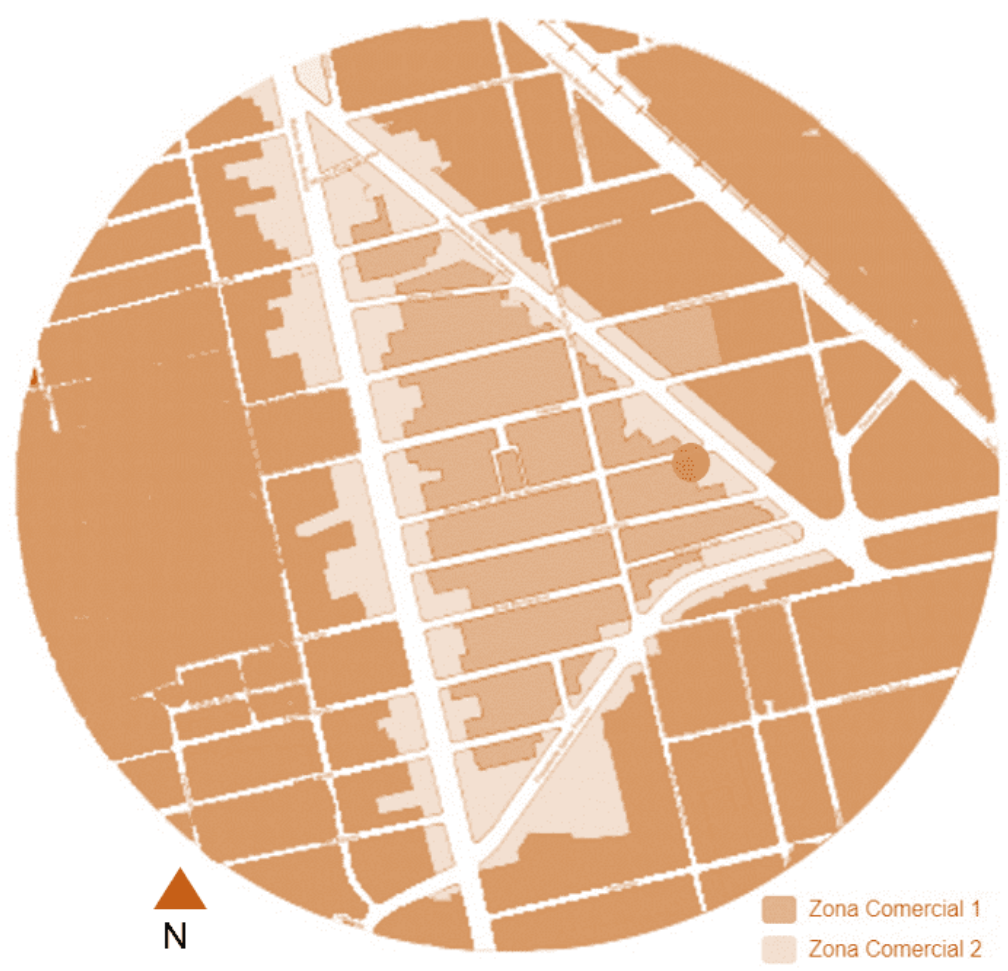

Fonte: Acervo pessoal (2019).

O terreno sugerido (figuras 6,7 e 8), apresenta topografia plana, atualmente sendo usado como o estacionamento Gran Park no centro da cidade de Juiz de Fora, com seu entorno possuindo um grande adensamento de edificações. Além do fácil acesso e visibilidade do terreno, a localidade, também, se aproxima de estabelecimentos de serviços e comércio, trazendo maior segurança.

RC: 101075

Disponível em: https://www.nucleodoconhecimento.com.br/arquitetura/acolhimentoas-vitimas 
Figura 6 - Imagem do terreno

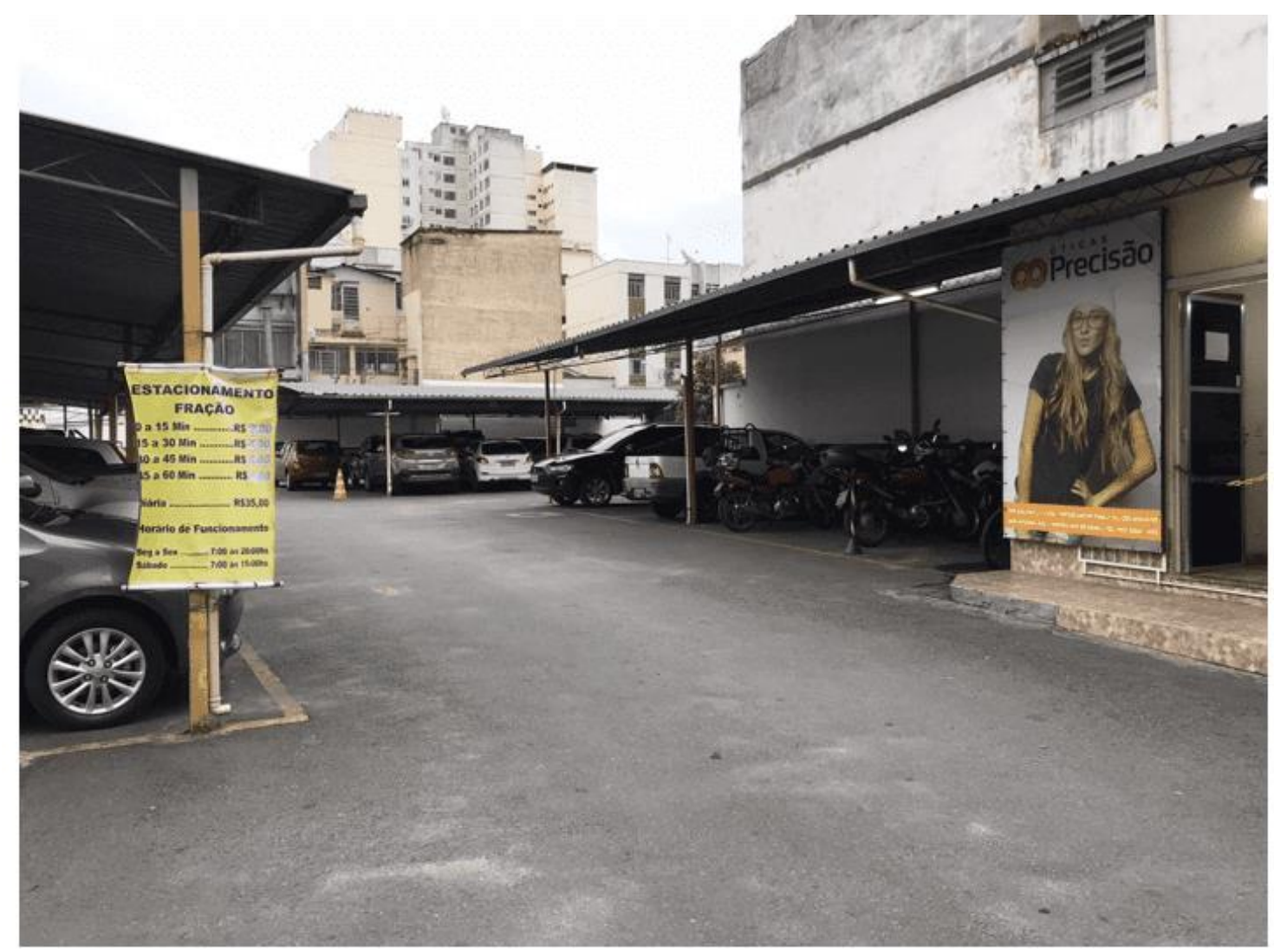

Fonte: Acervo pessoal (2019).

RC: 101075

Disponível em: https://www.nucleodoconhecimento.com.br/arquitetura/acolhimentoas-vitimas 
Figura 7 - Imagem do terreno

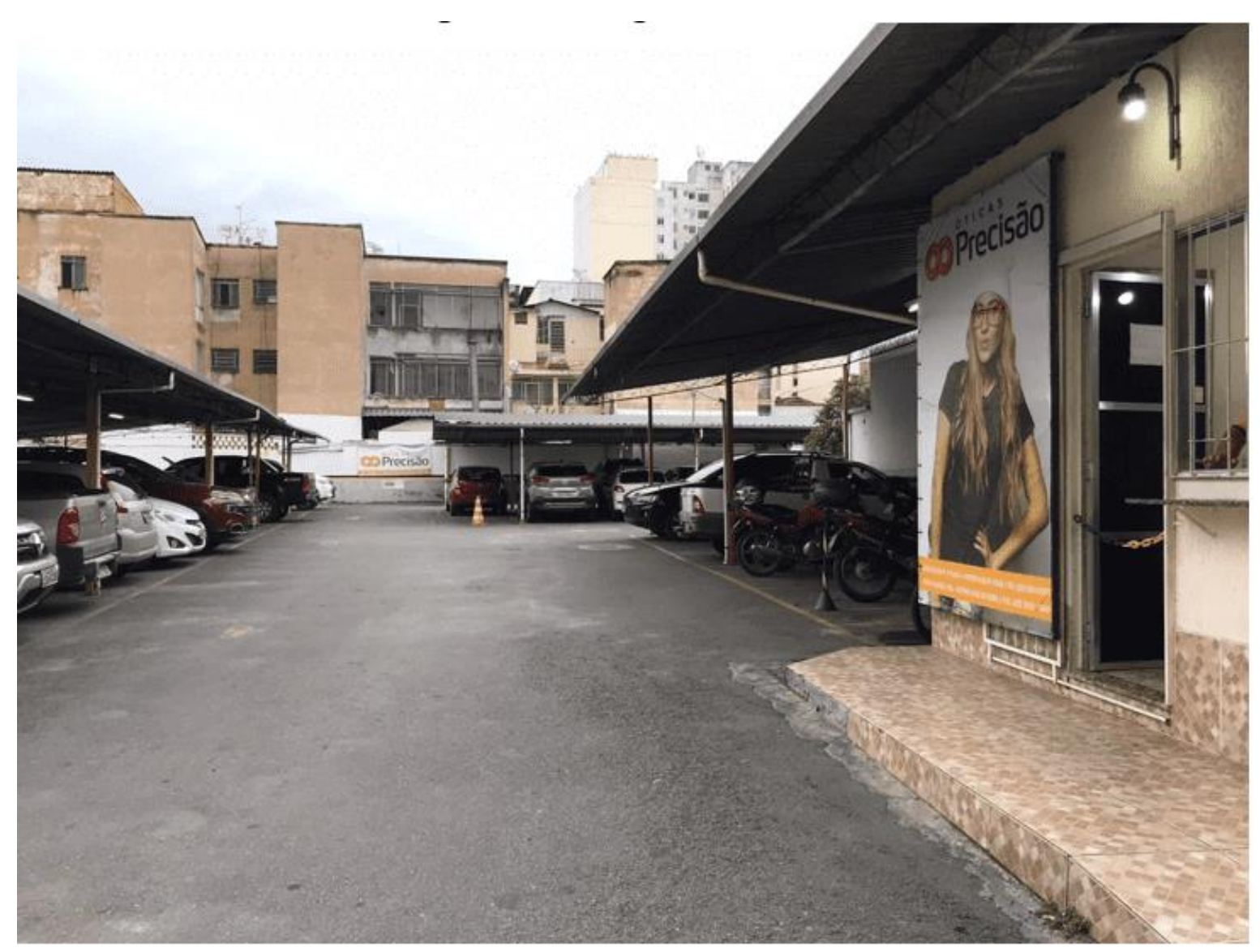

Fonte: Acervo pessoal (2019).

RC: 101075

Disponível em: https://www.nucleodoconhecimento.com.br/arquitetura/acolhimentoas-vitimas 
Figura 8 - Imagem do terreno

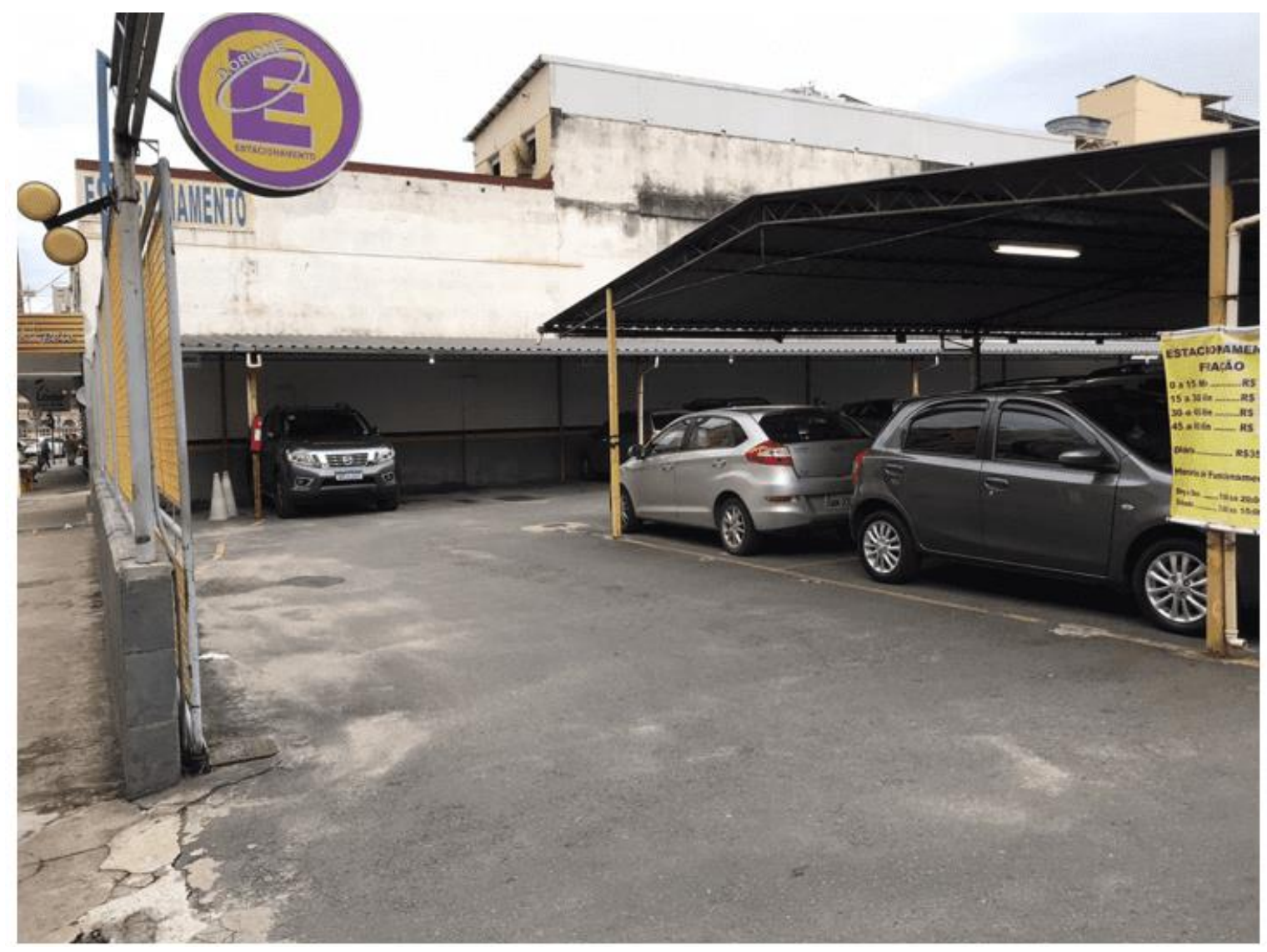

Fonte: Acervo pessoal (2019).

Em seu entorno imediato, possui edificações de porte médio, com usos comercial como padarias, farmácias, restaurantes, entre outros tipos de serviço, misto, com uso predominante de residências e comércios (figuras 9, 10, 11 e 12). No entorno não-imediato destaca-se edifícios residenciais, de uso misto e institucionais e encontra-se próximo de praças públicas, como o Parque Halfeld, sendo a mais imponente, e a praça da estação. Apresenta também empreendimentos de grande porte como, por exemplo, a prefeitura de Juiz de fora e a Cesama (Companhia de Saneamento Municipal), Catedral de Santo Antônio, supermercado Bretas e Bahamas. 
Figura 9 - Mapa de estudo do entorno

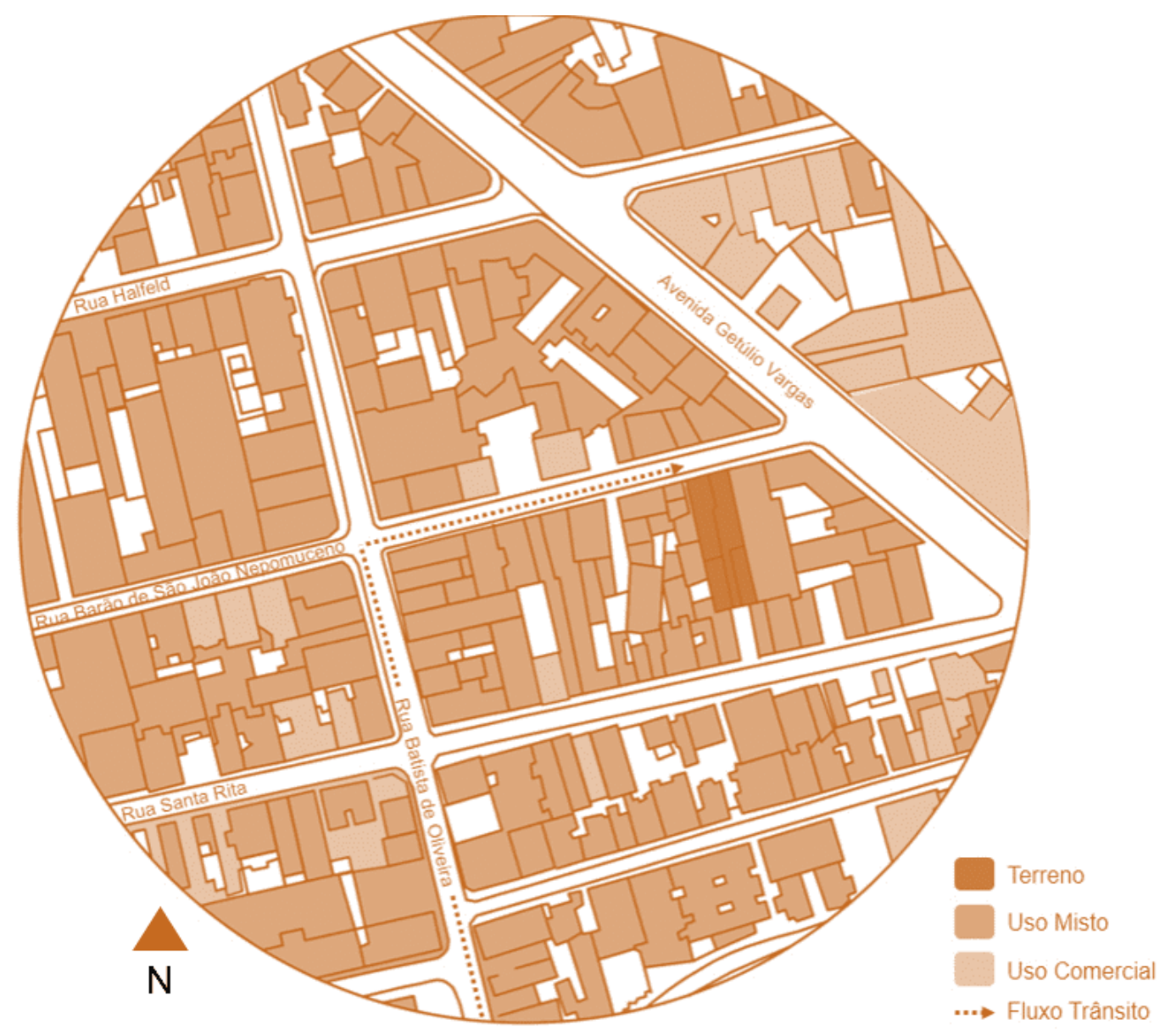

Fonte: Acervo pessoal (2019).

RC: 101075

Disponível em: https://www.nucleodoconhecimento.com.br/arquitetura/acolhimentoas-vitimas 
Figura 10 - Imagem do entorno imediato

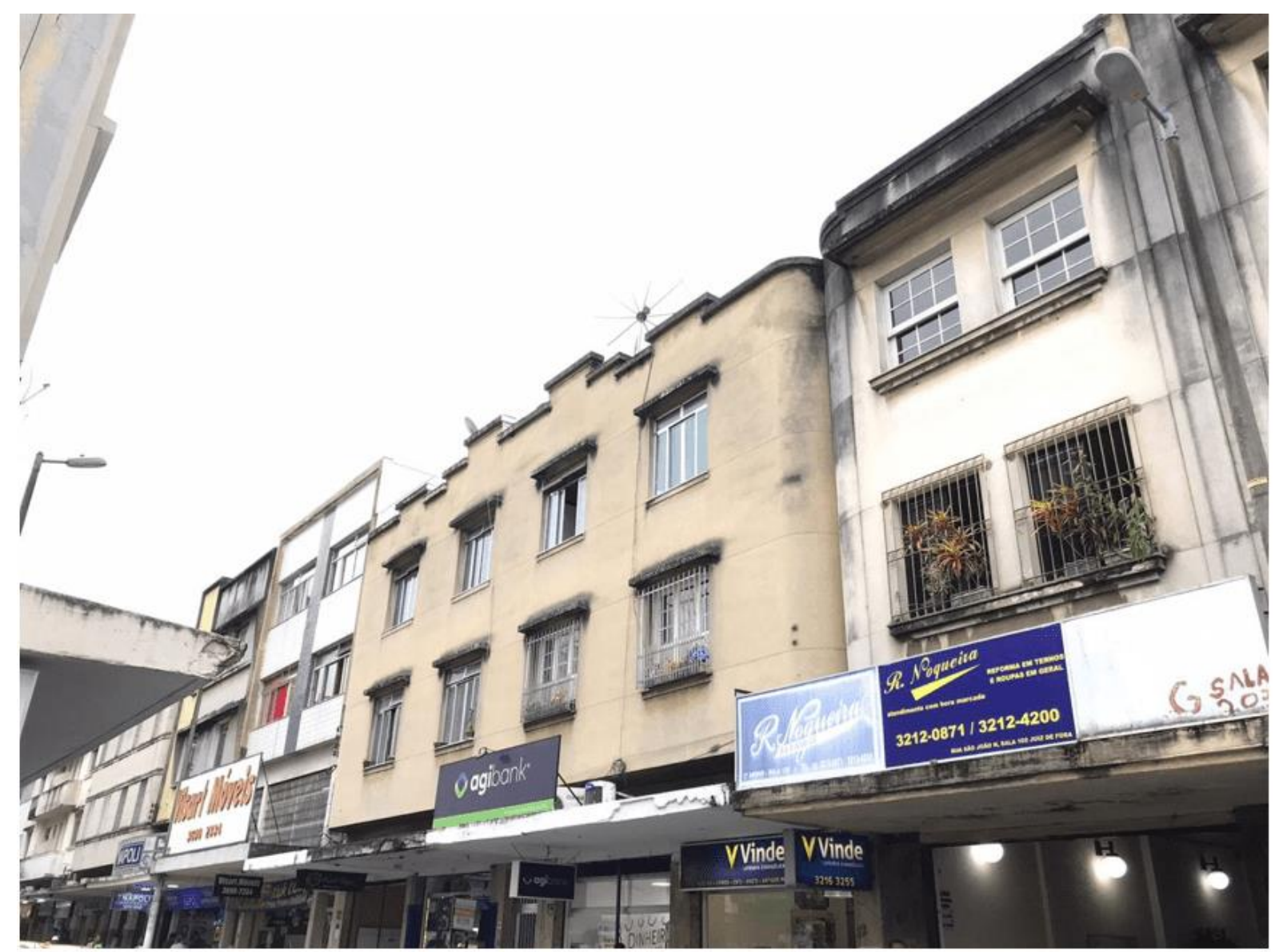

Fonte: Acervo pessoal (2019).

RC: 101075

Disponível em: https://www.nucleodoconhecimento.com.br/arquitetura/acolhimentoas-vitimas 
Figura 11 - Imagem do entorno imediato

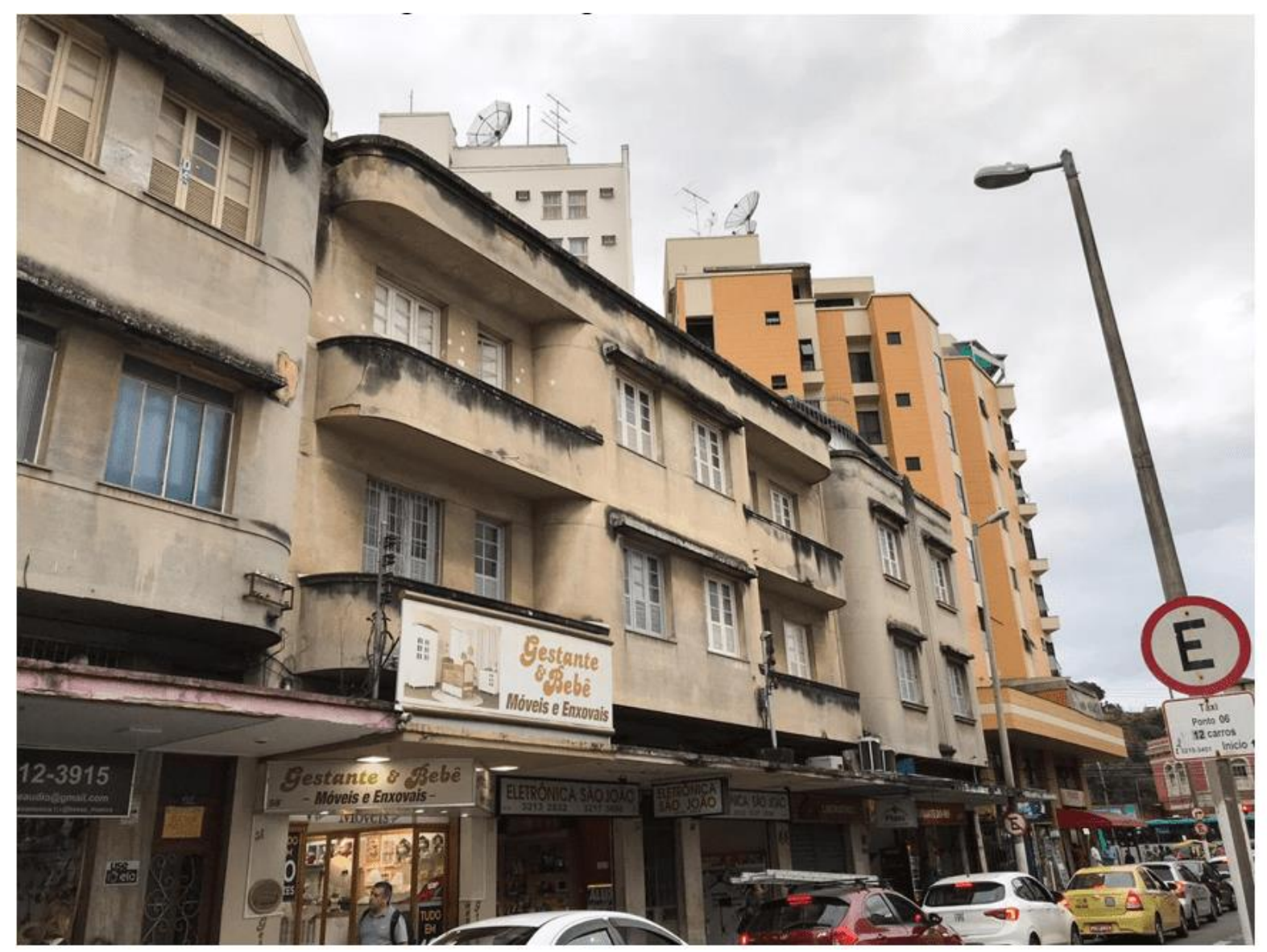

Fonte: Acervo pessoal (2019).

RC: 101075

Disponível em: https://www.nucleodoconhecimento.com.br/arquitetura/acolhimentoas-vitimas 
Figura 12 - Imagem do entorno imediato

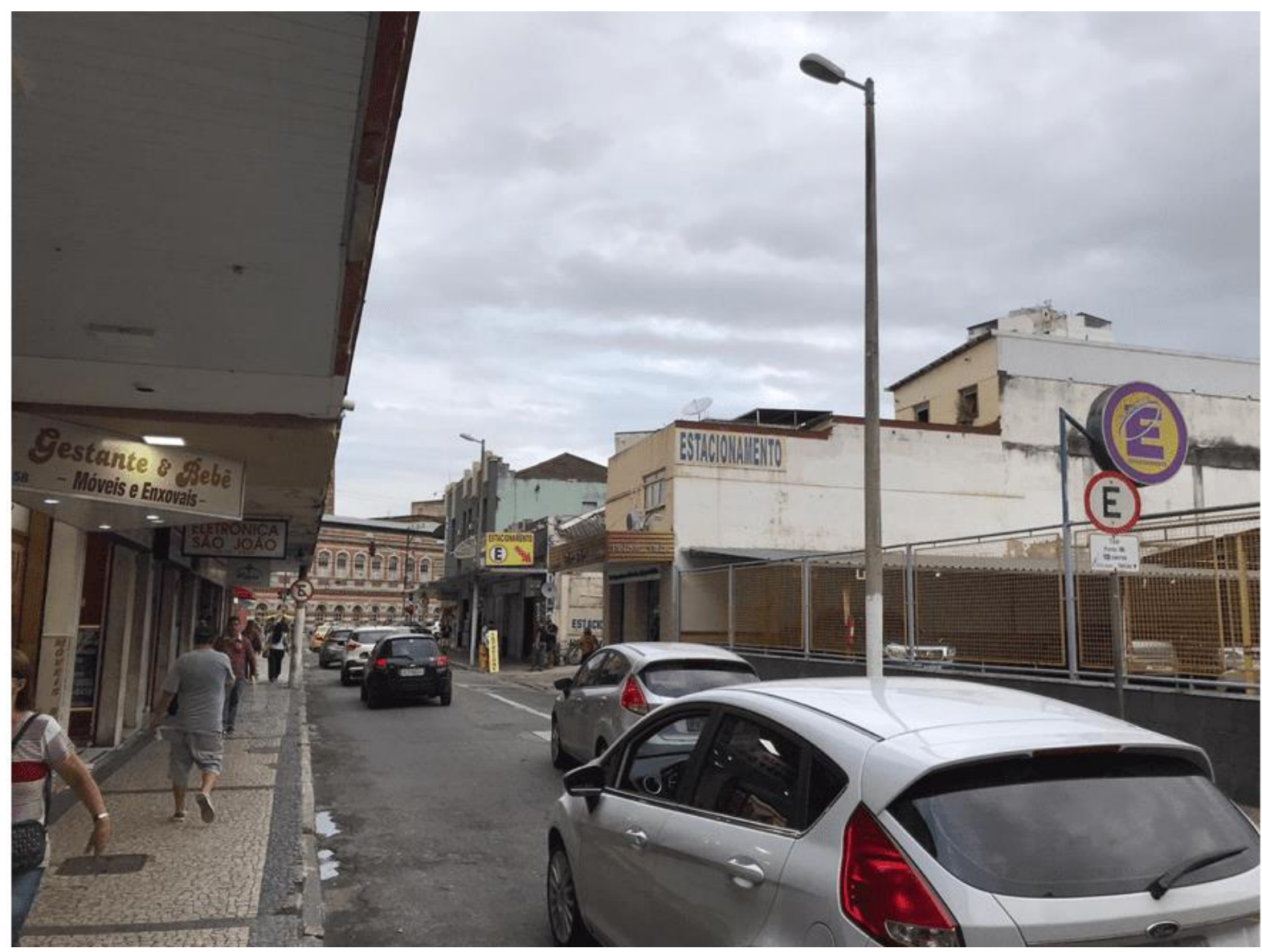

Fonte: Acervo pessoal (2019).

\section{RESULTADOS}

Baseado nos dados mapeados no decorrer do artigo, o Brasil é um país onde as casas de acolhimento para mulheres que sofrem violência doméstica são escassas, presentes em apenas 2,5\% das cidades do país, segundo IBGE (2013), através da matéria disponibilizada no site O Globo: Sociedade (2019). Juiz de Fora apresenta números elevados no que cerca a violência doméstica, por isso há necessidade de um suporte mais adequado, visto que boa parte das mulheres violentadas não denunciam por dependências, medo e por continuarem em contato com o agressor após a denúncia, fazendo com que não encontrem refúgio assegurando proteção a elas a seus filhos.

RC: 101075

Disponível em: https://www.nucleodoconhecimento.com.br/arquitetura/acolhimentoas-vitimas 
Em decorrências das pesquisas e dos resultados obtidos, o local de inserção do projeto foi determinado de acordo com as ocorrências dos bairros, e com isso, percebe-se que existem pontos críticos em quase todas as regiões do município, principalmente na Central, Oeste e Sul. Outros fatores importantes para essa escolha são a visibilidade do Centro de Apoio e a segurança, onde as mulheres consigam acessar com facilidade, cautela e confiança. Essa segurança é advinda do fluxo considerável de pessoas e veículos na área de inserção, demonstrada acima, e, também, pela localidade compreender os usos comercial e residencial predominantemente. É interessante que o Centro de Apoio tenha funcionamento 24 horas, para amparo em tempo integral, possua atividades para reinserção dessas mulheres e crianças para a sociedade, como cursos profissionalizantes, exercícios dinâmicos e lúdicos, palestras acerca do tema, apoio médico e psicológico, entre outras.

\section{CONSIDERAÇÕES FINAIS}

Em virtude dos fatos mencionados e expostos neste artigo, destaca-se que apesar da evolução dos debates em torno da violência doméstica, implementação e avanço da legislação em defesa da mulher, juntamente com políticas públicas e movimentos sociais, a tolerância da violência e do patriarcado no meio social ainda é presente, sendo uma grande barreira a combater-se. Porém é notório que com a criação de leis de proteção e espaços de refúgio, houve um aumento significativo no número de denúncias, pois a segurança e o amparo se tornaram mais vigentes.

Em detrimento dos números alarmantes e preocupantes da violência doméstica na cidade de Juiz de Fora, conclui-se que no município é necessária uma visão cautelosa e minuciosa sobre essa problemática, sendo a casa de apoio, para uma assistência mais pontual das vítimas, de grande relevância para que haja um auxílio maior sobre a vida delas.

Estudos no que se refere a violência e desigualdade históricas e da criação de casas de acolhimento a mulheres se fazem necessários e são de extrema importância, 
visto que quanto mais amparo legal as vítimas encontrarem mais seguras estarão de promover denúncias.

De acordo com os gráficos e dados indicados no decorrer do artigo, é insuficiente a quantidade de Casas-Abrigo existentes no Brasil com o objetivo de acolhimento a esse tipo de violência. Com isso, deu-se a sugestão de uma edificação com a finalidade de assegurar e abrigar as mulheres e seus filhos vítimas de violência doméstica na cidade de Juiz de Fora. Por isso a necessidade do aumento desses refúgios e de políticas públicas em favor da defesa da mulher traz grande significância.

\section{REFERÊNCIAS}

BADINTER, Elisabeth. Un Amour en Plus: histoire de l'amour maternel. 1. ed. Paris, Flamarrion: Nova Fronteira, 1980. p. 115-116.

BONDE NEWS. Prefeitura de Londrina vai reformar Casa Abrigo. Disponível em: https://www.bonde.com.br/bondenews/londrina/prefeitura-de-londrina-vai-reformarcasa-abrigo-356289.html. Acesso em: 5 set. 2019.

BRASIL DE FATO. Falta proteção contra violência doméstica nas cidades pequenas, diz Maria da Penha. Disponível em: https://www.brasildefato.com.br/2018/08/07/falta-protecao-contra-violenciadomestica-nas-cidades-pequenas-diz-maria-da-penha/. Acesso em: 10 set. 2019.

CARLOTO, Cássia Maria; CALÃO, Vanusa Ferreira. A Importância e o Significado da Casa Abrigo Para Mulheres em Situação De Violência Conjugal. Emancipação, Londrina, v. 6, n. 1, p. 209-212, 2006. Disponível em: https://www.revistas2.uepg.br/index.php/emancipacao/article/view/79/77. Acesso em: 20 set. 2019.

CONSELHO NACIONAL DE JUSTIÇA. CNJ Serviço: 0 que são e como funcionam as Casas-Abrigo. Disponível em: https://www.cnj.jus.br/cnj-servico-o- 
que-sao-e-como-funcionam-as-casas-

abrigo/\#: :text=As\%20Casas\%20abrigo\%20s\%C3\%A30\%20locais,o\%20curso\%20d e\%20suas\%20vidas. Acesso em: 12 set. 2019.

DOSSIÊ VIOLÊNCIA CONTRA AS MULHERES: Violência Doméstica e Familiar. Disponível

em: https://dossies.agenciapatriciagalvao.org.br/violencia/violencias/violencia-domesticae-familiar-contra-as-mulheres/. Acesso em: 18 set. 2019.

ÉPOCA. A Violência Contra a Mulher no Brasil em Cinco Gráficos. Disponível em: https://epoca.globo.com/a-violencia-contra-mulher-no-brasil-em-cinco-graficos23506457. Acesso em: 26 set. 2019.

G1: ZONA DA MATA, TV INTEGRAÇÃO. Zona da Mata é a 3a região com mais registros de violência doméstica em MG. Disponível em: https://g1.globo.com/mg/zona-da-mata/noticia/2019/05/13/zona-da-mata-e-a-3aregiao-com-mais-registros-de-violencia-domestica-em-mg.ghtml. Acesso em: 25 set. 2019.

GOMES, G. H. H. F; CURY, M. D. A. Perspectiva De Gênero Como Categoria de Análise Urbana: um Estudo Sobre a Implantação da Casa da Mulher de Juiz De Fora. X Congresso Brasileiro De Direito Urbanístico Grupo Temático 02: Direito À Cidade E O Combate Ao Racismo, Machismo, Lgbtfobia E Outras Formas E Opressão, Juiz de Fora, v. 1, p. 5-9, 2018.

GOUVEIA, Taciana. Ser, Fazer e Acontecer: Mulheres e o Direito à Cidade. 1.ed. Recife: SOS CORPO, 2008. p. 57.

INSTITUTO MARIA DA PENHA. Quem é Maria da Penha. Disponível em: https://www.institutomariadapenha.org.br/quem-e-maria-da-penha.html. Acesso em: 4 set. 2019.

RC: 101075

Disponível em: https://www.nucleodoconhecimento.com.br/arquitetura/acolhimentoas-vitimas 
JUSTIFICANDO: MENTES INQUIETAS PENSAM DIREITO. Casas-Abrigo: Como funcionam os refúgios para mulheres vítimas de violência doméstica. Disponível em: http://www.justificando.com/2018/11/19/casas-abrigo-comofuncionam-os-refugios-para-mulheres-vitimas-de-violencia-domestica/. Acesso em: 10 set. 2019 .

LONDRINA. Regimento Interno: Casa Abrigo canto de Dália. Prefeitura de Londrina - Secretaria Municipal de Política para as Mulheres. Londrina: SMPM, 2016

MIGUEL, Luiz Felipe; BIROLI, Flávia; Feminismo e Política: uma introdução. 1. ed. São Paulo: Boitempo editorial, 2014. p. 94-95 e 115.

NASCIMENTO, Laiane Nunes. Estupro Marital: O Inimigo Silencioso. 2015. 74 p. Trabalho de Conclusão de Curso (Graduação em Direito) - UniRV - Universidade de Rio Verde, Caiapônia - GO, 2015.

O GLOBO: SOCIEDADE. Treze anos após Lei Maria da Penha, só $2,4 \%$ das cidades têm casas-abrigo para mulheres. Disponível em: https://oglobo.globo.com/sociedade/celina/treze-anos-apos-lei-maria-da-penha-so24-das-cidades-tem-casas-abrigo-para-mulheres-23972179. Acesso em: 1 out. 2019

PROJETO COLABORA. JUNTOS POR UM MUNDO + SUSTENTÁVEL. Conheça 5 casas e uma plataforma que oferecem abrigo para LGBTs. Disponível em: https://projetocolabora.com.br/ods5/casas-dao-abrigo-para-lgbts/. Acesso em: 12 nov. 2019.

RIOSOLIDÁRIO: TRANSFORMANDO REALIDADES. Casa Abrigo Lar da Mulher. Disponível em: http://www.riosolidario.org/programas/mulheres/casa-abrigo-lar-damulher. Acesso em: 16 out. 2019. 
RIOS, GILMA MARIA. Amor E Violência: (Re) Leitura Dos Caminhos Das Mulheres Araguarinas Perante A Justiça. Natal-RN, Volume, Número, p. 1-2, jul./2018. http://www.snh2013.anpuh.org/resources/anais/27/1364931124_ARQUIVO_AMORE VIOLENCIATEXTOCOMPLETONATAL2013versao2.pdf. Acesso em: 12 set. 2019.

SENADO FEDERAL. Proteção às vítimas ainda é insuficiente. Disponível em: https://www12.senado.leg.br/emdiscussao/edicoes/saneamento-basico/violenciacontra-a-mulher/protecao-as-vitimas-ainda-e-insuficiente. Acesso em: 16 set. 2019.

SENADO FEDERAL. Violência doméstica e familiar contra a mulher: Pesquisa DataSenado. Senado Federal: subtítulo da revista, Local, v. 1, Número, p. 34-36, dez./2005. Disponível

em: https://www12.senado.leg.br/institucional/datasenado/arquivos/aumenta-numero-demulheres-que-declaram-ter-sofrido-violencia. Acesso em: 14 out. 2019.

TRIBUNA DE MINAS. Mais de mil mulheres pediram medidas protetivas este ano em JF. Disponível em: https://tribunademinas.com.br/noticias/cidade/21-082018/mais-de-mil-mulheres-pediram-medidas-protetivas-este-ano-em-jf.html. Acesso em: 24 out. 2019.

Enviado: Abril, 2021.

Aprovado: Novembro, 2021.

RC: 101075

Disponível em: https://www.nucleodoconhecimento.com.br/arquitetura/acolhimentoas-vitimas 